\title{
Cereblon Maintains Synaptic and Cognitive Function by Regulating BK Channel
}

\author{
iTae-Yong Choi, ${ }^{1,2 \star}$ Seung-Hyun Lee, ${ }^{1 \star}$ (ํ)Yoon-Jung Kim, ${ }^{1 *}$ Jae Ryul Bae, ${ }^{3}$ Kwang Min Lee,,${ }^{4,5}$ Youhwa Jo, ${ }^{1}$ \\ Soo-Jeong Kim, ${ }^{1}$ A-Ram Lee, ${ }^{4}$ Sekyu Choi, ${ }^{6}$ La-Mee Choi, ${ }^{1}$ Sunhoe Bang, ${ }^{6}$ Mi-Ryoung Song, ${ }^{4}$ Jongkyeong Chung, ${ }^{6}$ \\ Kyung Jin Lee, ${ }^{7}{ }^{\mathbb{C} S u n g}$ Hyun Kim, ${ }^{8} \mathbb{C}^{\circ}$ Chul-Seung Park, ${ }^{4}$ and ${ }^{\circledR}$ Se-Young Choi ${ }^{1}$ \\ ${ }^{1}$ Department of Physiology and Dental Research Institute, Seoul National University School of Dentistry, Seoul 03080, Republic of Korea, ${ }^{2}$ Department of \\ Neural Development and Disease, Korea Brain Research Institute, Daegu 41068, Republic of Korea, ${ }^{3}$ Department of Biomedical Science, Graduate School, \\ Kyung Hee University, Seoul 02447, Republic of Korea, ${ }^{4}$ School of Life Sciences, Gwangju Institute Science and Technology, Gwangju 61005, Republic of \\ Korea, ${ }^{5}$ Korea Food Research Institute, Seongnam, Gyeonggi 13539, Republic of Korea, ${ }^{6}$ National Creative Research Initiatives Center for Energy \\ Homeostasis Regulation, Institute of Molecular Biology and Genetics and School of Biological Sciences, Seoul National University, Seoul 08826, Republic of \\ Korea, ${ }^{7}$ Department of Medicine, University of Ulsan College of Medicine, Asan Medical Center, Seoul 05505, Republic of Korea, and ${ }^{8}$ Department of \\ Physiology, School of Medicine, Kyung Hee University, Seoul, 02447, Republic of Korea
}

Mutations in the cereblon (CRBN) gene cause human intellectual disability, one of the most common cognitive disorders. However, the molecular mechanisms of $C R B N$-related intellectual disability remain poorly understood. We investigated the role of $C R B N$ in synaptic function and animal behavior using male mouse and Drosophila models. Crbn knock-out (KO) mice showed normal brain and spine morphology as well as intact synaptic plasticity; however, they also exhibited decreases in synaptic transmission and presynaptic release probability exclusively in excitatory synapses. Presynaptic function was impaired not only by loss of CRBN expression, but also by expression of pathogenic CRBN mutants (human R419X mutant and Drosophila G552X mutant). We found that the BK channel blockers paxilline and iberiotoxin reversed this decrease in presynaptic release probability in $\mathrm{Crbn} \mathrm{KO}$ mice. In addition, paxilline treatment also restored normal cognitive behavior in $\mathrm{Crbn} \mathrm{KO}$ mice. These results strongly suggest that increased $\mathrm{BK}$ channel activity is the pathological mechanism of intellectual disability in CRBN mutations.

Key words: BK channels; CRBN; intellectual disability; neurotransmitter release; presynaptic

Significance Statement

Cereblon $(C R B N)$, a well known target of the immunomodulatory drug thalidomide, was originally identified as a gene that causes human intellectual disability when mutated. However, the molecular mechanisms of CRBN-related intellectual disability remain poorly understood. Based on the idea that synaptic abnormalities are the most common factor in cognitive dysfunction, we monitored the synaptic structure and function of Crbn knock-out (KO) animals to identify the molecular mechanisms of intellectual disability. Here, we found that Crbn KO animals showed cognitive deficits caused by enhanced BK channel activity and reduced presynaptic glutamate release. Our findings suggest a physiological pathomechanism of the intellectual disability-related gene $C R B N$ and will contribute to the development of therapeutic strategies for $C R B N$-related intellectual disability.

\section{Introduction}

Human intellectual disability, also widely known as mental retardation, is a psychiatric disease characterized by intelligence quotient scores lower than 70 and cognitive impairments such as decreases in language development, memory, and problem-solving skills (Greenspan and Woods, 2014). Intellectual disability is thought

\footnotetext{
Received July 24, 2017; revised March 1, 2018; accepted March 6, 2018.

Author contributions:C.-S.P. and S.-Y.C. designed research; T.-Y.C., S.-H.L., Y.-J.K., J.R.B., K.M.L., Y.J., S.-J.K., A.L., S.C., and L.-M.C. performed research; S.C., S.B., J.C., and K.J.L. contributed unpublished reagents/analytic tools; T.-Y.C., Y.-J.K., A.L., M.-R.S., J.C., and S.H.K. analyzed data; C.-S.P. and S.-Y.C. wrote the paper.

This work was supported by the National Research Foundation of Korea (Grants 2016-M3C7A1905481 and 2016-R1A2B4006811 to S.Y.C.), the Korea Healthcare Technology Research and Development Project (Grant HI13C1412 to C.S.P.), and GIST (GIST Research Institute Grant 2017 to C.S.P.). We thank Ms. Hui-Yeon Ko and Dr. Hojae Lee for participation in early experiments.
}

The authors declare no competing financial interests.

*T.-Y.C., S.-H.L., and Y.-J.K. contributed equally to this work.

Correspondence should be addressed to either of the following: Dr. Chul-Seung Park, School of Life Sciences, Gwangju Institute Science and Technology, Gwangju 61005, Republic of Korea, E-mail: cspark@gist.ac.kr; or Dr. Se-Young Choi, Department of Physiology, Seoul National University School of Dentistry, Seoul 03080, Republic of Korea, E-mail: sychoi@snu.ac.kr.

DOI:10.1523/JNEUROSCI.2081-17.2018

Copyright $\odot 2018$ the authors $\quad 0270-6474 / 18 / 383571-13 \$ 15.00 / 0$ 
to be caused by many different genetic etiological factors. Among them, a nonsense (c.1274C $>$ T) or missense $(c .1171 \mathrm{~T}>\mathrm{C})$ mutation in the CRBN gene, located on chromosome 3 (3p26.3) exon 11, is suspected to cause intellectual disability in humans (Higgins et al., 2004, 2008; Sheereen et al., 2017). Deletion or microduplication of 3p26.3 including CRBN also results in cognitive and behavioral impairment (Dijkhuizen et al., 2006; Papuc et al., 2015).

CRBN is a target of the drug thalidomide (Millrine and Kishimoto, 2017). Thalidomide was originally developed as a sedative, but was found to be severely teratogenic, upon which its use for sedation was discontinued (Vargesson, 2015). However, thalidomide and its derivatives (lenalidomide and pomalidomide) have recently been widely prescribed for multiple myeloma, myelodysplastic syndrome, and autoimmune diseases (Bartlett et al., 2004; Millrine and Kishimoto, 2017). The mechanism of CRBN function has been intensely investigated in the past decade. CRBN forms a CRL4 ${ }^{\text {CRBN }}$ E3 ubiquitin ligase complex with DNA-binding protein 1 (DDB1), cullin-4A (CUL4A), and regulator of cullins 1 (ROC1) as substrate receptors (Fischer et al., 2014; Liu et al., 2014). Thalidomide inhibits CRL4 ${ }^{\text {CRBN }}$ E3 ubiquitin ligase activity after binding to CRBN (Ito et al., 2010; Fischer et al., 2014; Liu et al., 2014). A large body of studies have identified the substrates of CRL4 ${ }^{\text {CRBN }}$ E3 ubiquitin ligase and the include AMP kinase (Lee et al., 2011), casein kinase 1A1 (Krönke et al., 2015), IKZF1 and 3 (Krönke et al., 2014; Lu et al., 2014; Zhu et al., 2014), MEIS2 (Fischer et al., 2014), glutamine synthetase (Nguyen et al., 2016, 2017), CLC channels (Hohberger and Enz, 2009; Ronstedt et al., 2015), and BK channels, which are large-conductance calciumactivated potassium channels (Jo et al., 2005; Liu et al., 2014). However, despite the fact that the study of $C R B N$ has evolved from its identification as a mild intellectual disability causal factor, the cellular and molecular mechanisms of cognitive impairment caused by $C R B N$ mutations remain unclear.

$\mathrm{Crbn}$ is widely expressed in the postmitotic period in most parts of the rodent brain, including the hippocampus, cerebral cortex, and cerebellum (Aizawa et al., 2011). We sought to investigate whether $C R B N$ mutations cause defects in the maintenance of synaptic structure and function, which are closely related to cognitive function. Here, we studied the synaptic and behavioral function of CRBN and $C R B N$-related intellectual disability using Crbn mutant animal models. Crbn knock-our (KO) mice, a loss-offunction animal model for $\mathrm{Crbn}$, have normal brain development, but exhibit impaired cognitive function similar to $C R B N$-mutated human intellectual disability patients (Higgins et al., 2004; Dijkhuizen et al., 2006; Papuc et al., 2015; Sheereen et al., 2017). Research into synaptopathy and channelopathy has determined the molecular mechanisms of cognitive disorders and identified genes and factors associated with neuropsychiatric diseases such as fragile $\mathrm{X}$ mental retardation and autism spectrum disorder (Vaillend et al., 2008; Pavlowsky et al., 2012). We applied this approach to Crbn mutant animal models and found that they had reduced neurotransmitter release at excitatory synapses because of increased BK channel activity.

\section{Materials and Methods}

\section{Experimental animals}

All mice were housed in an animal facility with a specific pathogen-free barrier under a $12 \mathrm{~h}$ light/dark cycle. Mice were allowed access to food and water ad libitum. Wild-type (WT) and Crbn KO male mice (Lee et al., 2013) from the C57BL/6 background were used. All experiments were approved by the Institutional Animal Care and Use Committee at Seoul National University and the Gwangju Institute of Science and Technology Animal Care and Use Committee. Drosophila strains were raised on a standard yeast, sugar, and agar medium at $25^{\circ} \mathrm{C}$. The WT strain was $w^{1118}$ unless otherwise noted. $C R B N^{\text {ex } 1}$ was generated by P-element imprecise excision of the GS14825 line (Kyoto Drosophila Genetic Resource Center, \#205969). Df(3R)BSC621 (a deficiency uncovering the CRBN locus, \#25696) and C155-GAL4 (pan-neuronal driver, \#458) were obtained from Bloomington Stock Center. The CRBN cDNA clone LD28592 was purchased from the Drosophila Genomics Resource Center (Indiana University, Bloomington, IN). UAS-Myc-CRBN and UAS-Myc-CRBN ${ }^{\mathrm{G} 552 \mathrm{X}}$ were generated by microinjection of pUAST vector-cloned DNA into w1118 embryos.

\section{Behavior tests}

Passive avoidance test. The passive avoidance test was performed using 10- to 11-week-old (WT vs KO experiment) male mice. The observer was blinded to the genotype or pharmacological treatment of the animal. The passive avoidance apparatus consisted of a light and dark chamber separated by a guillotine door. The floor of the dark chamber was made of stainless-steel grids. During habituation, mice were allowed to freely explore the box for $5 \mathrm{~min}$ with the door open and were then returned to their home cage. For conditioning, after $24 \mathrm{~h}$, the mice were placed into the light chamber and the sliding door was closed when both hindlimbs of the mice had entered into the dark chamber. Then, an electric foot shock $(0.25 \mathrm{~mA}, 2 \mathrm{~s})$ was delivered via the floor grids. Ten seconds later, the mice were returned to their home cage. Tests were performed $24 \mathrm{~h}$ after conditioning and the latency time required for mice to enter the dark chamber was measured with a $300 \mathrm{~s}$ cutoff.

Novel object recognition test. The novel object recognition test was performed using 10- to 11-week-old male mice. The mice were first habituated in a large plastic chamber $(22 \mathrm{~cm}$ wide $\times 27 \mathrm{~cm}$ long $\times 30 \mathrm{~cm}$ high $)$ for $7 \mathrm{~min}$ at $24 \mathrm{~h}$ intervals. After $2 \mathrm{~d}$ (training trials), the mice were presented with 2 objects and allowed to explore freely for $7 \mathrm{~min}$. In the testing trial performed $24 \mathrm{~h}$ later, a novel object was substituted for 1 of the 2 objects (the familiar objects) and the mice were scored for recognition over a 7 min period. Object recognition was defined as spending time oriented toward the object at a distance of $1 \mathrm{~cm}$ or less, touching the object, or sniffing with the nose. All of the objects were cleaned with ethanol after each session to remove odor cues. The observer was blinded to the genotype of the animal. Exploration times were recorded and discrimination time was calculated as follows: (exploration time with novel object - exploration time with familiar object)/(total exploration time).

Elevated plus maze (EPM) test. The EPM test was performed using 10to 11-week-old male mice. The EPM apparatus was a plus-shaped maze elevated $60 \mathrm{~cm}$ above the floor. It consisted of two closed arms surrounded by $30-\mathrm{cm}$-high opaque walls and two open arms $(110 \times 110$ $\mathrm{cm})$. Each mouse was placed in the center $(5 \times 5 \mathrm{~cm})$ of the maze facing one of the closed arms and allowed to explore the space for $15 \mathrm{~min}$. The movement of mice was tracked and recorded via an overhead video camera and further analyzed by real-time video-tracking computer software (Smart Version 2.5; Panlab). Time spent in the closed arms, center, and open arms was measured. The maze was cleaned with $70 \%$ ethanol and wiped with paper towels between each trial.

\section{Drug preparation and in vivo injection}

Paxilline (Tocris Bioscience) was dissolved to a 25 or $10 \mathrm{~mm}$ concentration in dimethylsulfoxide (DMSO) and then diluted 1:10 or 1:2000 in saline (the concentration of DMSO was $10 \%$ or $0.05 \%$, v/v). Paxilline were injected at $30 \mathrm{mpk}$ or $3 \mu \mathrm{g} / \mathrm{kg}$ body weight intraperitoneally. Ten percent DMSO was used for vehicle treatment.

\section{Primary neuronal culture and transfection}

Primary hippocampal neurons were isolated from the early postnatal day 0 (P0) to P1 WT and Crbn KO mice brains. Hippocampi were digested with trypsin (Invitrogen, 15090) and DNase (Sigma-Aldrich, DN25). Dissociated neurons were plated on poly-L-lysine coated coverslips at $3 \times$ $10^{5}$ cells per well. Neurons were maintained in neurobasal-A medium (Invitrogen, 10888-022) supplemented with B-27 (Invitrogen, 17504044), GlutaMAX-I (Invitrogen, 35050-061), and 1\% penicillin/streptomycin in a humidified $5 \% \mathrm{CO}_{2}$ incubator at $37^{\circ} \mathrm{C}$. Two days after plating, $2.5 \mu \mathrm{M}$ cytosine arabinoside was added to inhibit the non-neuronal cells. Twice a week thereafter, half of the medium was exchanged with fresh maintenance 
A $\quad$ wT

P2

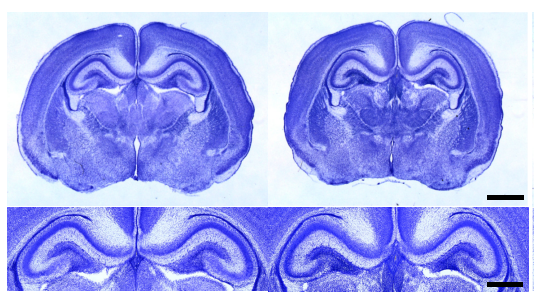

3 months

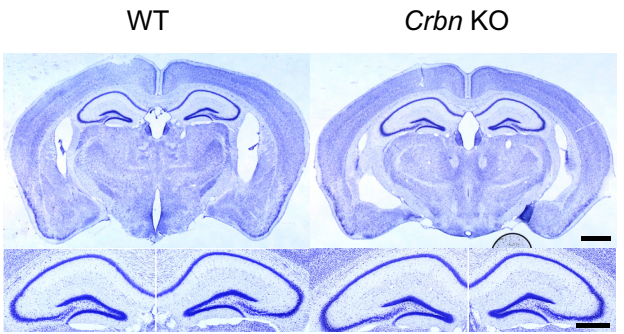

B

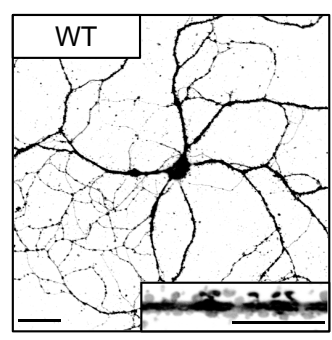

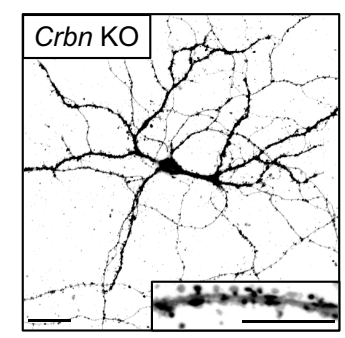

C

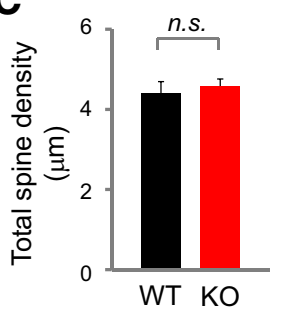

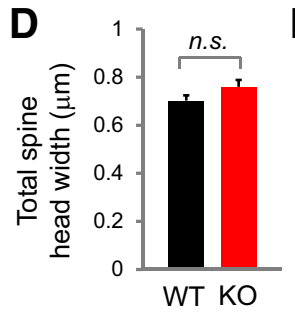
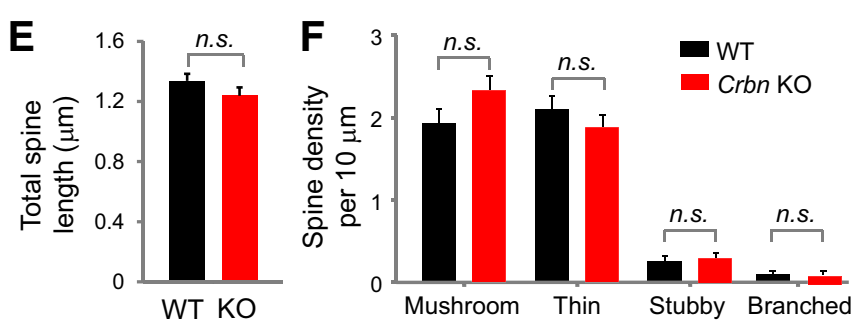

Figure 1. Crbn KO mice have normal brain architecture and spine morphology. $A$, Nissl stains of WT and Crbn KO whole brain sections (top) and hippocampus (bottom) at P2 and 3 months. Scale bar, $1 \mathrm{~mm}$ (top) and $0.5 \mathrm{~mm}$ (bottom). $\boldsymbol{B}$, Images of primary cultured hippocampal neurons from WT (left) and Crbn KO (right) mice labeled with Dil at 20 DIV (Scale bar, $50 \mu \mathrm{m}$ ). The morphology of the dendritic spines is shown in a high-magnification view in the bottom panel. Scale bar, $10 \mu \mathrm{m}$. $\boldsymbol{C}-\boldsymbol{E}$, No differences in total spine density $(\boldsymbol{C})$, total spine head-width $(\boldsymbol{D})$, or total spine length $(\boldsymbol{E})$ were seen between WT and $(\mathbf{r b n}$ KO neurons. $F$, No differences in spine densities of the different morphological categories (mushroom, thin, stubby, or branched types) were seen between WT and Crbn KO neurons. $n=37$ WT neurons; $n=28$ Crbn KO neurons. All data shown are mean \pm SEM. n.s., Not significant by independent Student's $t$ test.

medium. Cultured hippocampal neurons were transfected with DNA constructs (human wild CRBN and R419X) at $7 \mathrm{~d}$ in vitro (DIV7) using calcium phosphate. Experiments were performed at DIV9-14.

\section{Spine morphology analysis}

For the detailed spine morphology observation, we labeled cultured neurons using DiI (Invitrogen, D-282). Twenty DIV-cultured neurons were incubated with DiI $(5 \mu \mathrm{g} / \mathrm{ml})$ for $30 \mathrm{~min}$ at $37^{\circ} \mathrm{C}$. The stained cells were quickly washed in $1 \times$ PBS and fixed using $4 \%$ PFA. The fluorescence images were acquired using a Fluoview FV 1000 confocal laser-scanning microscope equipped with $100 \times$ and $60 \times$ oil-immersion objectives and capable of an additional $4 \times$ zoom. Spine density and morphology were analyzed using ImageJ software. Spine density was quantified based on morphological categories as described previously (Pak et al., 2001).

\section{Nissl staining}

P2 mice brains were harvested and immersed in 4\% paraformaldehyde in $0.1 \mathrm{M}$ phosphate buffer (PFA) for $2 \mathrm{~d}$ at $4^{\circ} \mathrm{C}$ and then transferred to PBS buffer for $1 \mathrm{~d}$ at $4^{\circ} \mathrm{C}$. Three-month-old mice were anesthetized with $20 \%$ urethane and then perfused transcardially with $4 \%$ PFA. After cardiac perfusion, whole brains were removed and postfixed for $1 \mathrm{~d}$. For cryosections, brains (both P2 and 3 months) were cryoprotected with $30 \%$ sucrose for $2 \mathrm{~d}$ and coronal sections of $40 \mu \mathrm{m}$ were cut with a cryostat (Leica) and stained with $0.1 \%$ cresyl violet for Nissl staining.

Immunohistochemistry of Drosophila larval neuromuscular junction (NMJs) Wandering third-instar larvae were dissected in $\mathrm{Ca}^{2+}$-free HL3.1 saline (Feng et al., 2004) and fixed in Bouin's fixative for 7 min. Larvae were washed with PBS containing $0.1 \%$ Triton $\mathrm{X}-100$ (PBT) and blocked in 5\% BSA in PBT for $1 \mathrm{~h}$. Samples were incubated with FITCconjugated anti-HRP (Jackson ImmunoResearch Laboratories) at 1:200 for $2 \mathrm{~h}$ at room temperature. Fluorescence images of NMJs labeled with anti-HRP were acquired with an FV300 laser-scanning confocal microscope (Olympus) and accompanying FLOUVIEW software using a Plan Apo $40 \times 0.90$ numerical aperture (NA) objective. All quantifications were performed at NMJ 6/7 in A2 segments. For analysis of NMJ morphology, confocal sections were maximally projected. Quantification of bouton number was performed as described previously (Lee et al., 2016).

\section{$q R T-P C R$ analysis}

Adults of WT and $C R B N^{\mathrm{ex} 1}$ were collected and RNA was isolated using QIAGEN's RNeasy Mini Kit. Total RNA $(1 \mu \mathrm{g})$ was reverse-transcribed by using M-MLV reverse transcriptase (Promega) to generate cDNA for qRT-PCR (Bio-Rad CFX96 Real-Time PCR Detection System and SYBR Green) using 500 nм primer concentrations and 2 ng of cDNA templates. The following primers were used to amplify Drosophila CRBN cDNA: 5'-GCAATTGGAGGACCAAC AGT-3' and 5' -ACATGTCACTGCTGGGA TGA-3'. The relative values were calculated using the $\Delta \Delta$ CT method via normalization to $\alpha$-tubulin mRNA levels.

\section{Electrophysiology}

Slice preparation. Using 3- to 5-week-old (both sexes) or 10- to 12-week-old (male) WT and $\mathrm{Crbn} \mathrm{KO}$ mice, transverse hippocampal slices (300 $\mu \mathrm{m}$ for whole-cell recordings or $400 \mu \mathrm{m}$ for extracellular field potential recordings) were prepared as described previously (Yang et al., 2011; Choi et al., 2015). After decapitation, brains were rapidly removed and placed in ice-cold, oxygenated $\left(95 \% \mathrm{O}_{2}\right.$ and $\left.5 \% \mathrm{CO}_{2}\right)$, low$\mathrm{Ca}^{2+} /$ high- $\mathrm{Mg}^{2+}$ dissection buffer containing the following (in $\mathrm{mM}$ ): 5 $\mathrm{KCl}, 1.23 \mathrm{NaH}_{2} \mathrm{PO}_{4}, 26 \mathrm{NaHCO}_{3}, 10$ dextrose, $0.5 \mathrm{CaCl}_{2}, 10 \mathrm{MgCl}_{2}$, and 212.7 sucrose. Slices were transferred to a holding chamber in an incubator containing oxygenated $\left(95 \% \mathrm{O}_{2}\right.$ and $\left.5 \% \mathrm{CO}_{2}\right)$ artificial CSF (ACSF) containing the following (in $\mathrm{mm}$ ): $124 \mathrm{NaCl}, 5 \mathrm{KCl}, 1.23$ $\mathrm{NaH}_{2} \mathrm{PO}_{4}, 2.5 \mathrm{CaCl}_{2}, 1.5 \mathrm{MgCl}_{2}, 26 \mathrm{NaHCO}_{3}$, and 10 dextrose at $28-$ $30^{\circ} \mathrm{C}$ for at least $1 \mathrm{~h}$ before recording.

Extracellular field potential recordings. After recovery, slices were transferred to a recording chamber where they were perfused continuously with oxygenated ACSF $\left(28-30^{\circ} \mathrm{C}\right)$ at a flow rate of $2 \mathrm{ml} / \mathrm{min}$. CA1 field EPSPs (fEPSPs) were evoked by Schaffer collateral (SC) stimulation $(0.2 \mathrm{~ms}$ current pulses) using a concentric bipolar electrode. Synaptic responses were recorded with ACSF-filled microelectrodes (1-3 M $\Omega$ ) and were quantified as the initial slope of fEPSP in CA1. Recordings were performed using an AM-1800 microelectrode amplifier (A-M Systems), a PG 4000A stimulator (Cygnus Technology), and a SIU-90 isolated current source (Cygnus Technology). Baseline responses were collected at $0.07 \mathrm{~Hz}$ with a stimulation intensity that yielded a $40-60 \%$ maximal response. NMDARdependent LTP was induced by high-frequency stimulation (HFS, 100 $\mathrm{Hz}$ for $1 \mathrm{~s}$ ) or four episodes of theta burst stimulation (TBS) at $10 \mathrm{~s}$ intervals. TBS consisted of 10 stimulus trains delivered at $5 \mathrm{~Hz}$; each train consisted of four pulses at $100 \mathrm{~Hz}$. NMDAR-dependent LTD was in- 
A

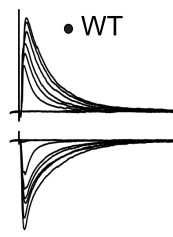

B

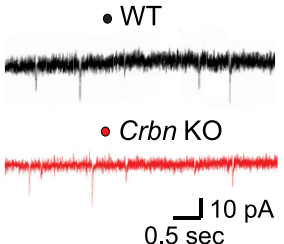

C

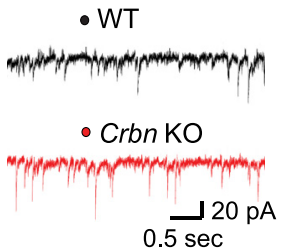

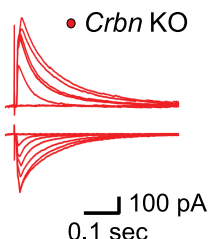

$0 . \overline{\mathrm{sec}}$
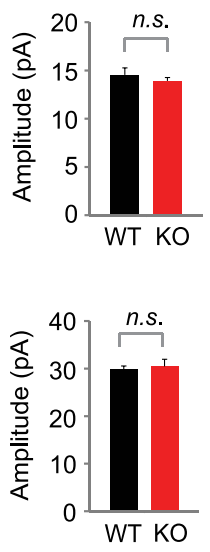
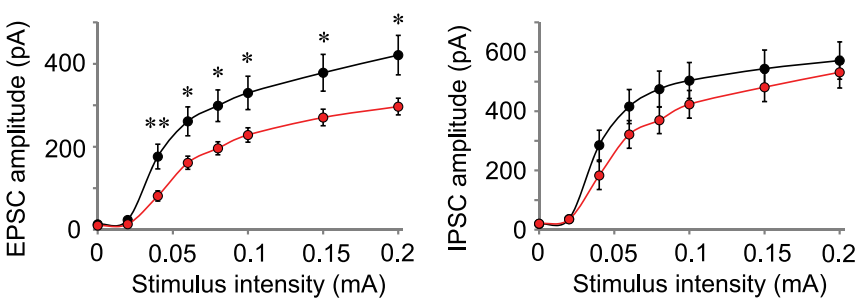

WT Crbn KO
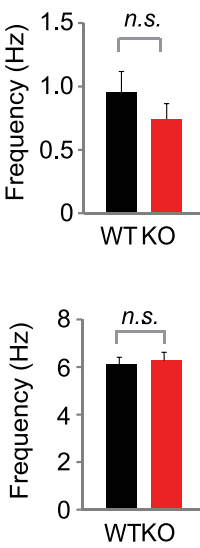

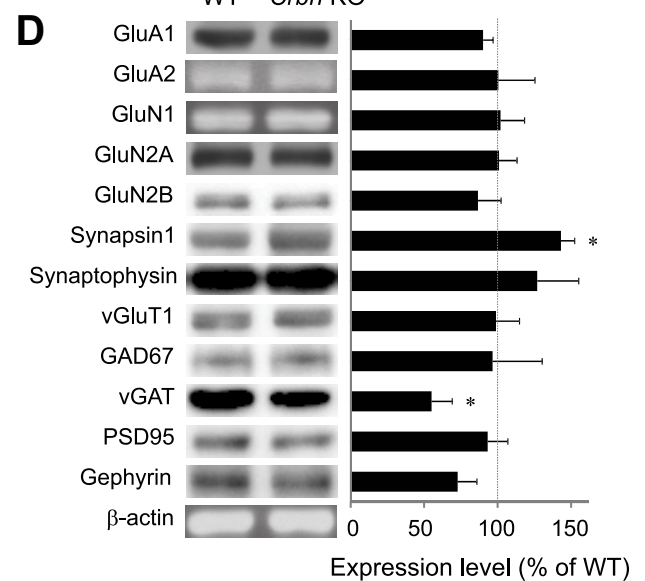

Figure 2. Basal synaptic transmission in SC-CA1 synapses and synaptic protein profiles of Cron K0 mice hippocampus. A, Left, representative traces of evoked EPSCs (eEPSCS) and evoked IPSCS (elPSCs) recorded with holding potentials of -70 and $0 \mathrm{mV}$ in hippocampal SC-CA1 synapses from WT (black trace) or Crbn KO (red trace) mice. Right, input/output relationship of eEPSCS (middle) or elPSCs (right) from WT (black bar) and Crbn K0 mice (red bar). Crbn K0 mice showed reduced eEPSC amplitudes than WT mice, but elPSCs were similar between two groups. $n=21,3$ (21 cells from 3 WT mice); $n=20,3$ (KO). $\boldsymbol{B}$, Representative traces (left), amplitude (middle), and frequency (right) of AMPAR-mEPSCs in hippocampal CA1 pyramidal neurons of WT (black trace) and (rbn K0 mice (red trace). Amplitude and frequency of AMPAR-mEPSCs were not significantly different between WT and Crbn KO mice. $n=19,4$ WT; $n=20,5$ KO. C, Representative traces (left), amplitude (middle), and frequency (right) of mIPSCs in hippocampal CA1 pyramidal neurons of WT (black trace) and K0 mice (red trace). Amplitude and frequency of mIPSCs were not significantly different between WT and Crbn KO mice. $n=27,3$ WT; $n=22,3$ KO. D. Hippocampal homogenates from 3- to 5 -week-old WT and Crbn KO mice were immunoblotted to evaluate the levels of several synaptic proteins. All protein signals were normalized relative to $\beta$-actin levels before comparisons between genotypes were made. Synapsin I was increased and vGAT was decreased significantly in Crbn K0 mice, but the expression levels of other synaptic proteins were similar between two groups. $n=4 \mathrm{WT} ; n=5 \mathrm{KO}$. All data shown are mean \pm SEM. ${ }^{* *} p<0.01$; ${ }^{*} p<0.05$. n.S., Not significant by independent Student's $t$ test.

duced by low-frequency stimulation (LFS; 900 pulses at $1 \mathrm{~Hz}$ for $900 \mathrm{~s}$ ). Long-lasting LTP (L-LTP) was induced by 4 trains of HFS separated by 5 min intervals. Group I mGluR-dependent LTD was induced by $10 \mathrm{~min}$ bath-application of $100 \mu \mathrm{M}(\mathrm{R}, \mathrm{S})-3,5-\mathrm{DHPG}$ (Tocris Bioscience). Data from slices with stable recordings ( $<5 \%$ change over the baseline period) were included in the analysis. All data are presented as mean \pm SEM normalized to the preconditioning baseline (at least $20 \mathrm{~min}$ of stable responses). The experimenters were blinded to mouse genotypes. IGOR software (Wavemetrics) was used for digitizing and analyzing the responses.

Whole-cell recordings. After recovery, slices were transferred to a recording chamber where they were perfused continuously with ACSF gassed with $95 \% \mathrm{O}_{2} / 5 \% \mathrm{CO}_{2}$ at a flow rate of $2 \mathrm{ml} / \mathrm{min}$. Slices were equilibrated for 5 min before the recordings and all of the experiments were performed at $23-25^{\circ} \mathrm{C}$. All recordings were performed in hippocampal CA1 pyramidal neurons identified by their size and morphology. Recordings were obtained using a Multiclamp 700B amplifier (Molecular Devices) under visual control with differential interference contrast illumination in an upright microscope (Olympus, BX51WI). Patch pipettes (4-6

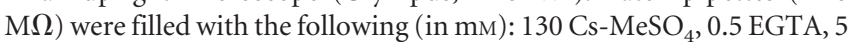
TEA-Cl, $8 \mathrm{NaCl}, 10$ HEPES, 1 QX-314, 4 ATP-Hg, 0.4 GTP-Na, 10 phosphocreatine- $\mathrm{Na}_{2}, 0.1$ spermine [for the miniature ESPC (mEPSC), excitatory ESPC (eEPSC), and eIPSC experiments], $130 \mathrm{CsCl}$, 1.1 EGTA, $2 \mathrm{MgCl}_{2}, 0.1 \mathrm{CaCl}_{2}, 10 \mathrm{NaCl}, 10 \mathrm{HEPES}, 2 \mathrm{ATP}-\mathrm{Na}$ (for mIPSC experiments), $135 \mathrm{~K}$-gluconate, $8 \mathrm{NaCl}, 10$ HEPES, $2 \mathrm{ATP}-\mathrm{Na}$, and $0.2 \mathrm{GTP}-\mathrm{Na}$ (for calcium-activated potassium current experiments) (Aoki and Baraban, 2000) at a $\mathrm{pH}$ of 7.4 and $280-290 \mathrm{mOsm}$. The extracellular recording solution consisted of ACSF supplemented with picrotoxin $(100 \mu \mathrm{M})$, TTX $(1 \mu \mathrm{M})$, and DL-AP5 (50 $\mu \mathrm{M})$ for mEPSC experiments, picrotoxin $(100 \mu \mathrm{M})$ for the eEPSC experiment, TTX $(1 \mu \mathrm{M})$, CNQX $(20 \mu \mathrm{M})$ and
DL-AP5 $(50 \mu \mathrm{M})$ for the mIPSC experiment, CNQX $(20 \mu \mathrm{M})$ and DLAP5 $(50 \mu \mathrm{M})$ for the eIPSC experiment, and TTX $(1 \mu \mathrm{M})$ for measurement of calcium-activated potassium currents. Evoked synaptic responses were elicited by SC stimulation ( $0.2 \mathrm{~ms}$ current pulses) using a concentric bipolar electrode placed $200-300 \mu \mathrm{m}$ in front of the postsynaptic pyramidal cell. All eEPSC and eIPSC recordings were conducted in an external solution containing elevated divalent cations $\left(4 \mathrm{mM} \mathrm{Ca}^{2+}\right.$ and $\mathrm{Mg}^{2+}$ ) to reduce network excitability and prevent polysynaptic responses upon stimulation (Clem and Huganir, 2010). Only cells with an access resistance $<20 \mathrm{M} \Omega$ and an input resistance $>100 \mathrm{M} \Omega$ were studied. The cells were discarded if the input or the access resistance changed $>20 \%$. Data were acquired and analyzed using pClamp 10.2 (Molecular Devices). Signals were filtered at $2 \mathrm{kHz}$ and digitized at $10 \mathrm{kHz}$ with Digidata 1440A (Molecular Devices).

Drosophila NMJ recordings Two-electrode voltage-clamp (TEVC) recordings of wandering third-instar female Drosophila larvae NMJ were obtained from ventral longitudinal muscle 6 in segment A3-A4 at room temperature as described previously with modifications (Karr et al., 2009). All dissections and recording were performed in HL3.1 saline containing the following (in mM): $70 \mathrm{NaCl}, 5 \mathrm{KCl}, 4 \mathrm{MgCl}_{2}, 5$ trehalose, 115 sucrose, and 5 HEPES (Feng et al., 2004). Larval dissection was performed in $\mathrm{Ca}^{2+}$-free saline to minimize muscle contraction. TEVC recording was performed with $2 \mathrm{mM} \mathrm{Ca}^{2+}$. Recording electrodes were filled with $3 \mathrm{M}$ $\mathrm{KCl}$, which had a resistance of 10-15 M $\Omega$. Recordings were made from cells with an initial resting membrane potential between -60 and -70 $\mathrm{mV}$ at a holding potential of $-70 \mathrm{mV}$ with a Geneclamp 500 amplifier (Molecular Devices). The cut segmental nerve was stimulated with a glass suction electrode at a suprathreshold level $(5 \mathrm{~mA})$ for $0.2 \mathrm{~ms}$. Signals were filtered at 10,000 Hz, acquired with Axoscope version 10.2 software (Molecular Devices), and analyzed with Clampfit version 10.2 software 
A

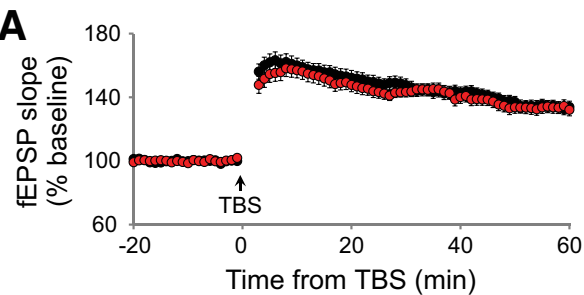

B

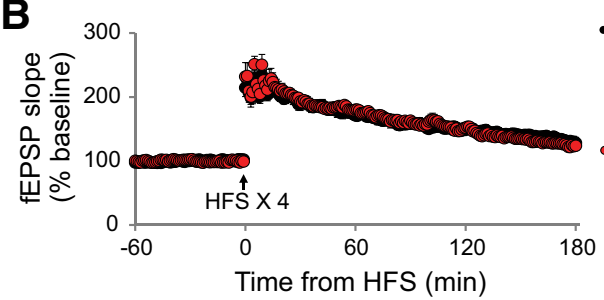

C

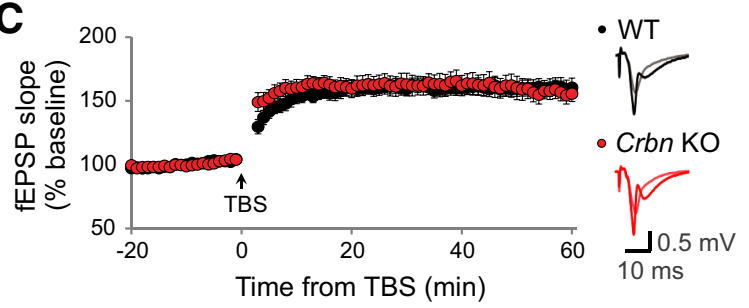

D

E

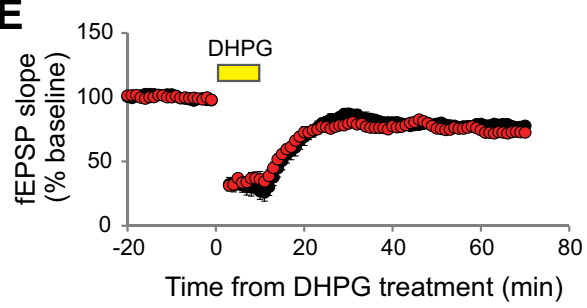

- WT
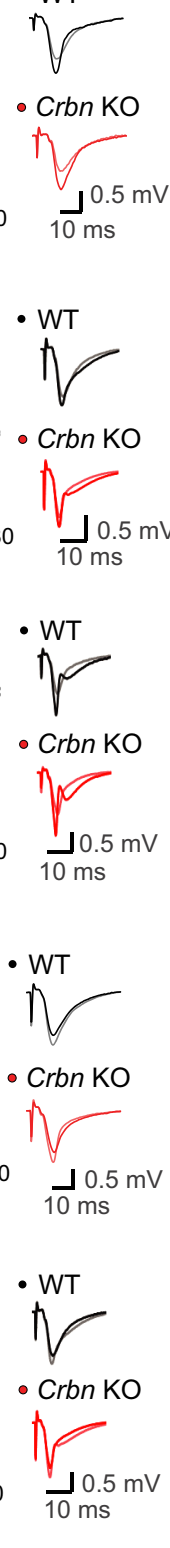
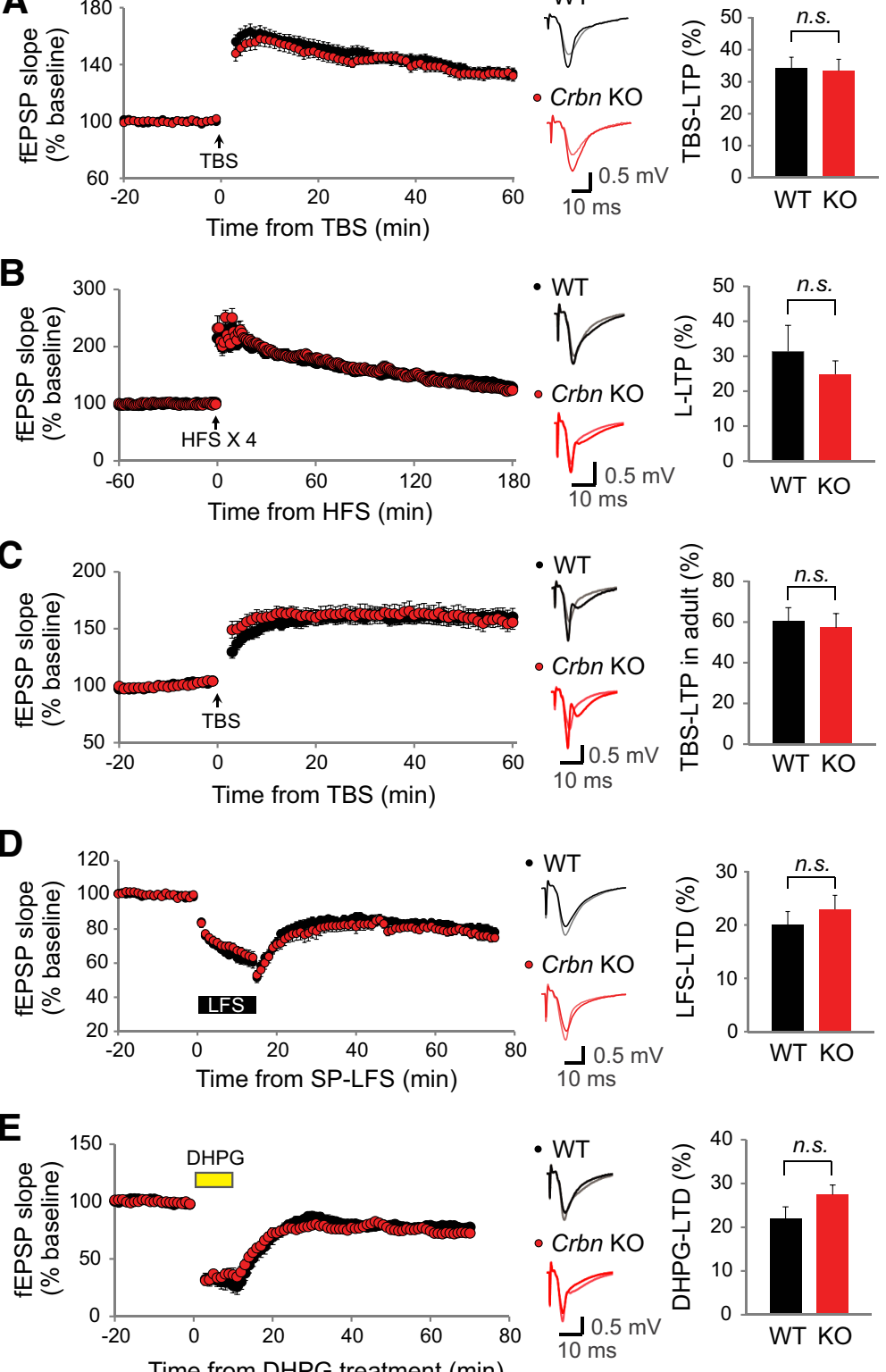

Figure 3. Crbn K0 mice exhibit normal long-term synaptic plasticity in hippocampal SC-CA1 synapses. $\boldsymbol{A}, \boldsymbol{B}$, No differences were seen in LTP in hippocampal SC-CA1 synapses from 3- to 5-week-old Crbn K0 mice; NMDAR-dependent early-phase TBS-LTP $(n=$ 27 cells from 7 WT mice; $n=28$ cells from 8 Crbn K0 mice, compared with last 10 min average after tetanic stimulation) $(\boldsymbol{A})$ and L-LTP induced by four repeated HFS (HFS $\times 4$ ) with 5 min intervals $(n=11,7$ (WT); $n=9,6$ (K0) compared with last 10 min average after tetanic stimulation) $(\boldsymbol{B})$. C, No differences in NMDAR-dependent TBS-LTP in hippocampal SC-CA1 synapses from 10to 12-weeks old WT and Crbn K0 mice ( $n=13,8 \mathrm{WT} ; n=10,5 \mathrm{KO}$ compared with last 10 min average after tetanic stimulation). $\boldsymbol{D}, \boldsymbol{E}$, No differences in long-term depression in hippocampal SC-CA1 synapses from 3- to 4-week-old Crbn KO mice; NMDARdependent LFS-LTD ( $n=13,3 \mathrm{WT} ; n=8,4 \mathrm{KO}$ ) compared with last 10 min average after tetanic stimulation (D) and group I mGluR-dependent LTD (mGluR-LTD) induced by 10 min bath-application of $100 \mu \mathrm{M}(\mathrm{R}, \mathrm{S})$-3,5-DHPG ( $n=7,3 \mathrm{WT} ; n=6,2 \mathrm{KO}$ compared with last 10 min average after tetanic stimulation) $\boldsymbol{E}$, Left, fEPSP slope was plotted before and after stimulation. Middle, Sample traces represent fEPSPs at 1 min before (gray is WT, pink is KO) and 1 or 3 (only for L-LTP experiment) h after (black is WT, red is $\mathrm{KO}$ ) conditioning stimulation. Right, Magnitudes of long-term synaptic plasticity were calculated by comparing the average slopes of fEPSPs recorded during the last 10 min with those recorded before stimulation. All data shown are mean \pm SEM. n.s., Not significant by independent Student's $t$ test.

(Molecular Devices). EPSC amplitudes were measured from peak to the baseline immediately before EPSC onset.

Live imaging and analysis of neurotransmitter release with $v$ Glut1-pHluorin

To measure vesicle release, neurons were transfected with vesicular glutamate transporter-pHluorin $(\mathrm{vG}-\mathrm{pH})$ as described previously (Ariel and Ryan, 2010; Kim and Ryan, 2013). Coverslips were mounted in a stimulation chamber with laminar flow perfusion on the stage of a custom-built laser-illuminated epifluorescence microscope. Live images were acquired with an iXon Ultra 897 (Andor Technology, DU-897U-CS0-\#BV) back-illuminated EM CCD camera. A diode-pumped OBIS 488 laser (Coherent) shuttering by synchronizing the TTL on/off signal from the EMCCD camera during acquisition was used as a light source. Fluorescence excitation/emission and collection were achieved using a $40 \times(1.3 \mathrm{NA})$ Fluar Zeiss objective lens with 500-550 nm emission and $498 \mathrm{~nm}$ dichroic filters (Chroma) for pHluorin. Action potentials were evoked by passing a $1 \mathrm{~ms}$ current pulse through platinum-iridium electrodes from an isolated current stimulator (World Precision Instruments). Neurons were perfused in saline-based buffer containing the following (in mM): $119 \mathrm{NaCl}, 2.5 \mathrm{KCl}, 2 \mathrm{CaCl}$, $2 \mathrm{MgCl} 2,25 \mathrm{HEPES}$, and 30 glucose, along with $10 \mu \mathrm{M}$ CNQX and $50 \mu \mathrm{M}$ AP5 (adjusted to $\mathrm{pH}$ 7.4). All experiments were performed at $30^{\circ} \mathrm{C}$. For image analysis, ImageJ was used with the plugin Time-series analyzer. vGlut1-pH+ boutons were selected as a region of interest (oval, diameter: 8 pixels). Fluorescence traces were analyzed with Origin Pro-8.0.

\section{Brain slice biotinylation assay}

Biotinylation assays were performed using hippocampal slices as described previously (Gabriel et al., 2014). Hippocampal slices (300 $\mu \mathrm{m}$ thick) were prepared from 5- to 7-week-old $\mathrm{WT}$ and male $\mathrm{Crbn} \mathrm{KO}$ mice. The slices were incubated for $40 \mathrm{~min}$ at $31^{\circ} \mathrm{C}$ in oxygenated ACSF. To biotinylate the cell surface proteins, slices were treated with sulfo-NHS-SS-biotin (Thermo Scientific, 21328) in ACSF under gentle shaking at $4^{\circ} \mathrm{C}$ for $45 \mathrm{~min}$. The slices were then incubated twice at $4^{\circ} \mathrm{C}$ for $25 \mathrm{~min}$ in quenching solution (100 mM BSA in ACSF). The quenched slices were lysed in $400 \mu \mathrm{l}$ of ice-cold RIPA buffer containing protease inhibitor mixture (Sigma-Aldrich, 11836153001) and incubated for $1 \mathrm{~h}$ on ice. The lysates were then centrifuged at $14,000 \times g$ for $15 \mathrm{~min}$ at $4^{\circ} \mathrm{C}$ and supernatant was collected. Protein concentrations were determined using the BCA Protein Assay Kit (Thermo Scientific, 23225). To isolate biotin-labeled proteins, $200 \mu \mathrm{g}$ lysates were added to $40 \mu \mathrm{l}$ of streptavidin-agarose beads (Thermo Scientific, 29200) and rotated at $4^{\circ} \mathrm{C}$ overnight. The beads were washed with lysis buffer and eluted with $2 \times$ Laemmli sample buffer. Surface (biotin-labeled) and input ( $10 \%$ of total, $20 \mu \mathrm{g}$ ) proteins were analyzed via Western blot.

\section{Western blot analysis}

Hippocampal slices from 3- to 5-week-old WT and CRBN KO male mice were prepared using the same method of slice preparation as for electrophysiology. Samples were homogenized in ice-cold lysis buffer (T-PER tissue protein extraction reagent; Thermo Scientific, 78510) combined with a protease inhibitor mixture (Sigma-Aldrich, P8340). Homogenates were centrifuged at $13,000 \mathrm{rpm}$ for $30 \mathrm{~min}$ at $4^{\circ} \mathrm{C}$ and supernatants were stored at $-80^{\circ} \mathrm{C}$. Protein concentrations were measured using the BCA Protein Assay Kit 
(Thermo Scientific, 23225). Equal amounts (30 $\mu \mathrm{g})$ of protein were loaded into the lanes of a SDS polyacrylamide gel (10\%). Separated proteins were then transferred onto PVDF membranes, blocked with 5\% skim milk in TBST for $1 \mathrm{~h}$ at room temperature, and incubated overnight with primary antibodies for immunoblotting. Membranes were washed with TBST and then incubated with HRP-conjugated secondary antibodies for $1 \mathrm{~h}$. HRP was detected using SuperSignal West Pico Chemiluminescent substrate (Thermo Scientific, 34080) and a BioImage Analyzer (Bio-Rad ChemiDoc MP). Membranes were stripped with Restore Western blot Stripping Buffer (Thermo Scientific, $21059)$ and reprobed for $\beta$-actin.

\section{Antibodies}

The following primary antibodies were used: GluA1 (Abcam, ab31232, 1:500), GluA2 (Millipore, MAB397, 1:500), GluN1 (Thermo Scientific, PA3-102, 1:1000), GluN2A (Santa Cruz Biotechnology, sc-1468, 1:1000), GluN2B (Santa Cruz Biotechnology, sc-1469, 1:1000), synapsin1 (Millipore, AB1543, 1:500), synaptophysin (Santa Cruz Biotechnology, sc-9116, 1:1000), vGluT1 (Millipore, MAB5502, 1:500), GAD67 (Millipore, MAB5406, 1:5000), vGAT (Millipore, AB5062P, 1:500), PSD95 (Thermo Scientific, MA1-046, 1:2000), gephyrin (Santa Cruz Biotechnology, sc-6411, 1:1000), BK channel (BD Biosciences, 611249, 1:500), and $\beta$-actin (Santa Cruz Biotechnology, sc-47778, 1:1000). HRP-conjugated anti-mouse (Abcam, ab6728, 1:10,000), anti-rabbit (Abcam, ab6802, 1:10,000), and anti-goat (Jackson Immunoresearch Laboratories, 805-035-180, 1:10,000) IgG H\&Ls were used as secondary antibodies.

\section{Statistical analysis}

Data analyses and graphical display were performed with SigmaPlot version 11.0 software (Systat Software). All displayed values represent the mean \pm SEM. Significant differences between groups were determined using independent or paired Student's $t$ tests or MannWhitney $U$ test and multiple comparisons were performed using two-way ANOVA.

\section{Results}

Crbn KO mice show normal brain and synaptic morphology

We first tested whether the cognitive impairments of Crbn mutants were due to abnormal neurodevelopment because the inhibitory target of thalidomide is CRBN and thalidomide causes abnormal limb development. When Nissl-stained brain sections of WT and Crbn KO mice were examined, however, no appreciable anatomical abnormalities were detected in $\mathrm{P} 2$ or 3-month-old mice (Fig. 1A). Morphological changes in synaptic structure generally affect the cognitive function of mammalian brains (Kasai et al., 2010). However, we found no significant differences in the density (Fig. $1 C$; $t_{(63)}=-0.489, p=0.626$ ), head-width (Fig. $1 D ; t_{(63)}=-1.626$, $p=0.109$ ), or length of dendritic spines (Fig. $1 E ; t_{(63)}=1.378$, $p=0.173$ ) between WT and Crbn KO neurons. Analysis revealed that the density of the four different types of dendritic spines (mushroom $\left(t_{(63)}=-1.484, p=0.143\right)$, thin $\left(t_{(63)}=1.066, p=\right.$

A
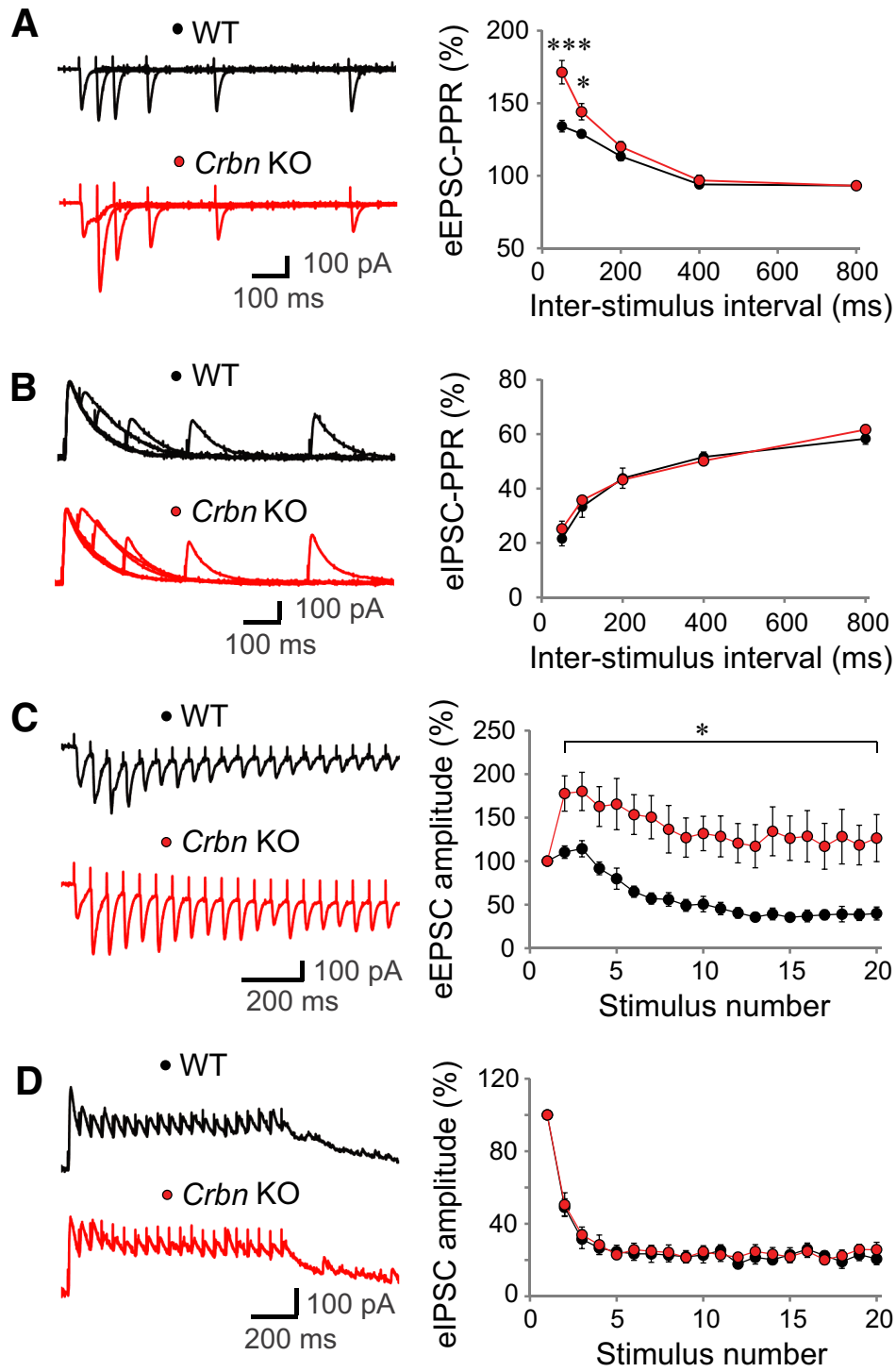

Figure 4. Excitatory, but not inhibitory, presynaptic neurotransmitter release is reduced in hippocampal SC-CA1 synapses of Crbn KO mice. $\boldsymbol{A}, \boldsymbol{B}$, Left, Representative traces of PPR of eEPSCs $(\boldsymbol{A})$ or elPSCS $(\boldsymbol{B})$ in hippocampal SC-CA1 synapses from WT (black trace) or Crbn KO mice (red trace). Right, eEPSC-PPR or eIPSC-PPR was plotted against ISIs. $n=13,2$ WT; $n=15,3 \mathrm{KO}$ (for the eEPSC-PPR experiment), $n=12,2 \mathrm{WT} ; n=12,2 \mathrm{KO}$ (for the elPSC-PPR experiment). eEPSC-PPR was increased in (rbn K0 mice and sponses of eEPSCS (C) or eIPSCS (D) in hippocampal SC-CA1 synapses from WT (black trace) or Crbn K0 mice (red trace). Right, Relative amplitudes of eEPSC $s$ or elPSCs were plotted against stimulus number. STP in excitatory synaptic transmission induced by 20 pulses at $20 \mathrm{~Hz}$ stimulation was increased in Crbn KO mice (second $\sim 20^{\text {th }}$ stimulus, ${ }^{*} p<0.05$ ). $n=8,2 \mathrm{WT} ; n=8,2 \mathrm{KO}$ for the eEPSC-STP experiment; $n=13,2$ WT; $n=12,2$ K0 for the eIPSC-STP experiment; ${ }^{* * *} p<0.001$.

$0.291)$, stubby $\left(t_{(63)}=-0.472, p=0.639\right)$, and branched $\left(t_{(63)}=\right.$ $-0.0355, p=0.972)$ ) was not significantly affected by Crbn deficiency (Fig. $1 F$ ). These results demonstrated that lack of CRBN did not affect the macroscopic or microscopic architecture of the mouse brain significantly and strongly suggested that the defects in learning and memory found in $\mathrm{Crbn} \mathrm{KO}$ mice were unlikely to be related to brain structural abnormalities.

Crbn KO mice show normal long-term synaptic plasticity but reduced excitatory neurotransmitter release

We next characterized synaptic function in Crbn $\mathrm{KO}$ animals. We found that basal excitatory synaptic transmission measured by the amplitude of evoked eEPSCs against stimulus intensity (SI) was decreased (Fig. 2A; SI at $0.04 \mathrm{~mA}: t_{(39)}=2.893, p=0.006$; SI 

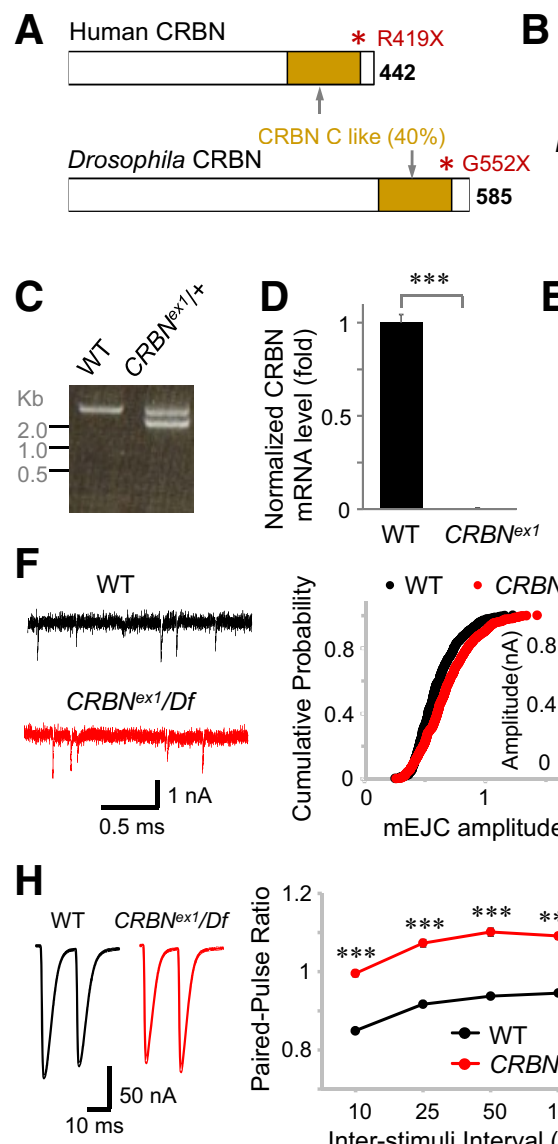
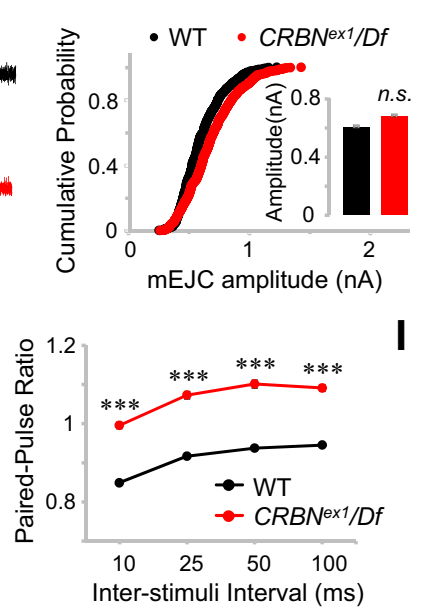
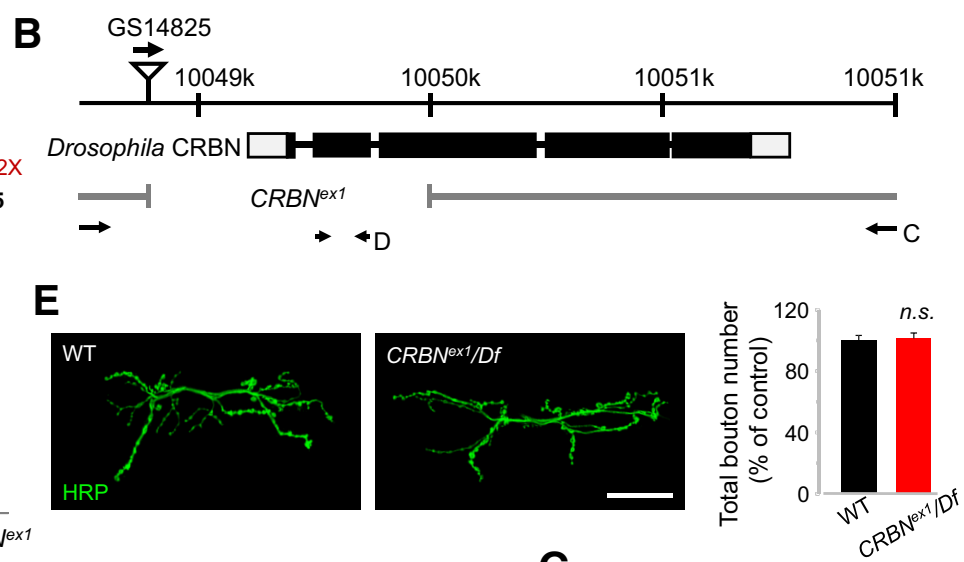

G
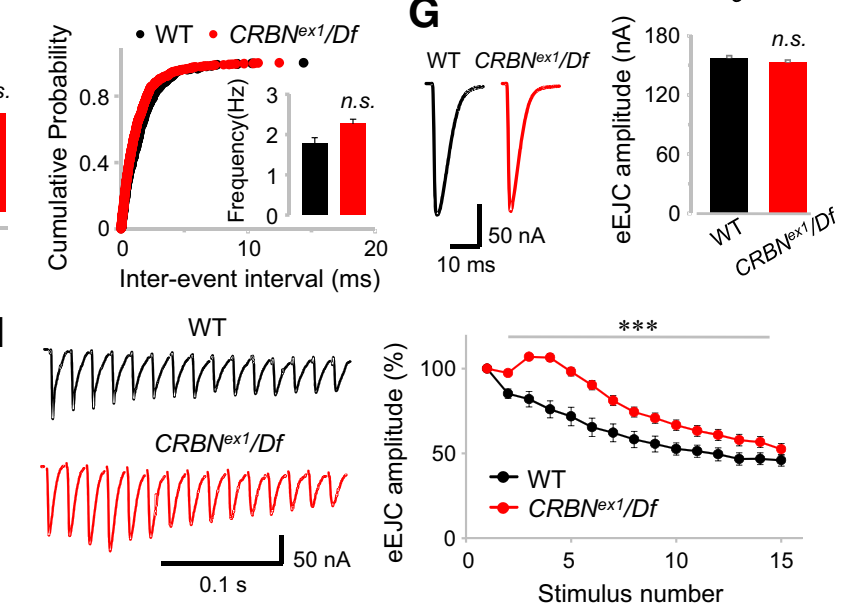

Figure 5. Drosophila Crbn mutants have decreased probability of neurotransmitter release. $A$, Domain structures of human CRBN and its Drosophila ortholog with percentage identity between their corresponding domains. CRBN C-like domain is shown in dark yellow. The single asterisks denote substitution mutations of CRBN used in this study. $\boldsymbol{B}$, Genomic map of Drosophila CRBN locus. The exons of CRBN are indicated by boxes and the coding regions are colored black. The 1160 bp deleted regions (3R10048848 10050008) for CRBN null mutants (CRBN ex1) are also presented. C, Genomic PCR analyses in WT WT, heterozygous $C R B N$ mutants ( $\left.C R B N N^{\text {ex1 }} /+\right)$ using the ( primer set in $\boldsymbol{B}$. D, qRT-PCR analysis for $C R B N$ using the $D$ primer set in $\boldsymbol{B}$. $\boldsymbol{E}$, Representative confocal images of anti-HRP labeled Drosophila Crbn mutants third-instar larval NMJ 6/7. Scale bar, $50 \mu \mathrm{m}$. Quantification of total bouton number as a percentage of the control. $n=9 \mathrm{WT} ; n=8$ (CRBN $\left.{ }^{\mathrm{ex} 1} / \mathrm{Df}\right)$. $\boldsymbol{F}$, Spontaneous mEJCs of the NMJ synapses in Drosophila Crbn mutant. Representative traces (left), mEJC amplitude (middle), and mEJC frequency (right). $n=12$ WT; $n=17$ CRBN ${ }^{\text {ex } 1 / D f . ~} \mathbf{G}$, eEJC in Crbn mutant. Representative traces (left) and eEJC amplitude (right). $n=12$ WT; $n=15$ (CRBN ${ }^{\mathrm{ex} 1} / \mathrm{Df}$ ). $\boldsymbol{H}$, Decreased PPR in Crbn mutant larvae. Representative traces (left) and PPR is plotted against indicated ISIs (right). $n=15 \mathrm{WT} ; n=11$ CRBN ${ }^{\mathrm{ex} 1} / \mathrm{Df}$. I, STP induced by 20-pulse train stimulation in Crbn mutant flies. Representative traces (left) and the amplitudes of eEJCs are plotted against stimulus number (right). $n=20 \mathrm{WT} ; n=11\left(R B N^{\mathrm{ex} 1} / \mathrm{Df} ;{ }^{* * *} p<0.001\right.$.

at $0.06 \mathrm{~mA}: t_{(39)}=2.568, p=0.014 ; \mathrm{SI}$ at $0.08 \mathrm{~mA}: t_{(39)}=2.453$, $p=0.019$; SI at $0.10 \mathrm{~mA}: t_{(39)}=2.267, p=0.029$; SI at $0.15 \mathrm{~mA}$ : $t_{(39)}=2.177, p=0.036$; SI at $\left.0.20 \mathrm{~mA}: t_{(39)}=2.358, p=0.023\right)$, but basal inhibitory synaptic transmission measured by the amplitude of eIPSCs against SI (Fig. $2 A ; p>0.05$ at all SIs) in hippocampal SC-CA1 synapses of $\mathrm{Crbn} \mathrm{KO}$ mice. Crbn $\mathrm{KO}$ mice and WT mice showed no differences in mEPSCs Fig. $2 B$; amplitude: $t_{(37)}=0.782, p=0.439$; frequency: $\left.t_{(37)}=1.056, p=0.298\right)$ or mIPSCs (Fig. 2C; amplitude: $t_{(47)}=0.397, p=0.693$; frequency: $\left.t_{(47)}=-0.341, p=0.734\right)$ in hippocampal CA1 pyramidal neurons. We compared the expression levels of several synaptic proteins that are important for maintaining and regulating synaptic structure and function in the hippocampal tissues of WT and $\mathrm{Crbn} \mathrm{KO}$ mice. Levels of most synaptic proteins, including glutamate receptor subunits GluA1 $\left(t_{(7)}=0.511, p=0.625\right)$, GluA2 $\left(t_{(7)}=-0.0187, p=0.986\right)$, GluN1 $\left(t_{(7)}=-0.103, p=0.921\right)$, GluN2A $\left(t_{(7)}=-0.0724, p=0.944\right)$, GluN2B; excitatory (PSD95, $t_{(7)}=0.376, p=0.718$ ) and inhibitory (gephyrin, $t_{(7)}=0.200$, $p=0.847$ ) postsynaptic proteins, and excitatory (synaptophysin, $t_{(7)}=-0.688, p=0.513$; vGluT1, $\left.t_{(7)}=0.0498, p=0.962\right)$ and inhibitory (GAD67 $\left(t_{(7)}=0.0838, p=0.936\right)$ presynaptic proteins, were identical in WT and Crbn KO mice (Fig. 2D). Crbn KO mice showed slightly increased synapsin I expression $\left(t_{(7)}=-3.089\right.$, $p=0.018$ ) and decreased vGAT expression (Fig. $2 D ; t_{(7)}=0.371$, $p=0.05)$; however, the physiological relevance and mechanism of these changes were not clear.

Long-term synaptic plasticity such as LTP or LTD is a cellular and/or molecular mechanism of learning and memory and is impaired in Crbn KO mice (Neves et al., 2008). Therefore, we tested whether $\mathrm{Crbn} \mathrm{KO}$ mice show impaired long-term synaptic plasticity. Three- to 4-week-old Crbn KO mice exhibited normal induction of NMDAR-dependent TBS-LTP (Fig. $3 A ; t_{(53)}=$ $0.155, p=0.877$ ) and protein synthesis-dependent L-LTP (Fig. $\left.3 B ; t_{(18)}=0.402, p=0.877\right)$. The induction of LTP in 10 - to 12-week-old Crbn $\mathrm{KO}$ animals was also intact (Fig. $3 C$; $t_{(21)}=$ 0.340, $p=0.737$ ). We confirmed that Crbn KO mice also had normal NMDAR-dependent LFS-LTD (Fig. $3 D ; t_{(19)}=0.793$, $p=0.438)$ and $100 \mu \mathrm{M}$ DHPG-induced mGluR-dependent LTD (Fig. $3 E ; t_{(11)}=1.649, p=0.127$ ).

However, $\mathrm{Crbn} \mathrm{KO}$ mice showed an increased paired-pulse ratio (PPR) in excitatory [Fig. 4A; interstimulus interval (ISI) at $50 \mathrm{~ms}$ : $t_{(26)}=-3.933, p<0.001$; ISI at $100 \mathrm{~ms}: t_{(26)}=-2.349, p=0.027$; ISI at $200 \sim 800 \mathrm{~ms}: p>0.05$ ] but not inhibitory synaptic transmission (Fig. 4B; ISI at $20 \sim 800$ ms: $p>0.05$ ), implying decreased 


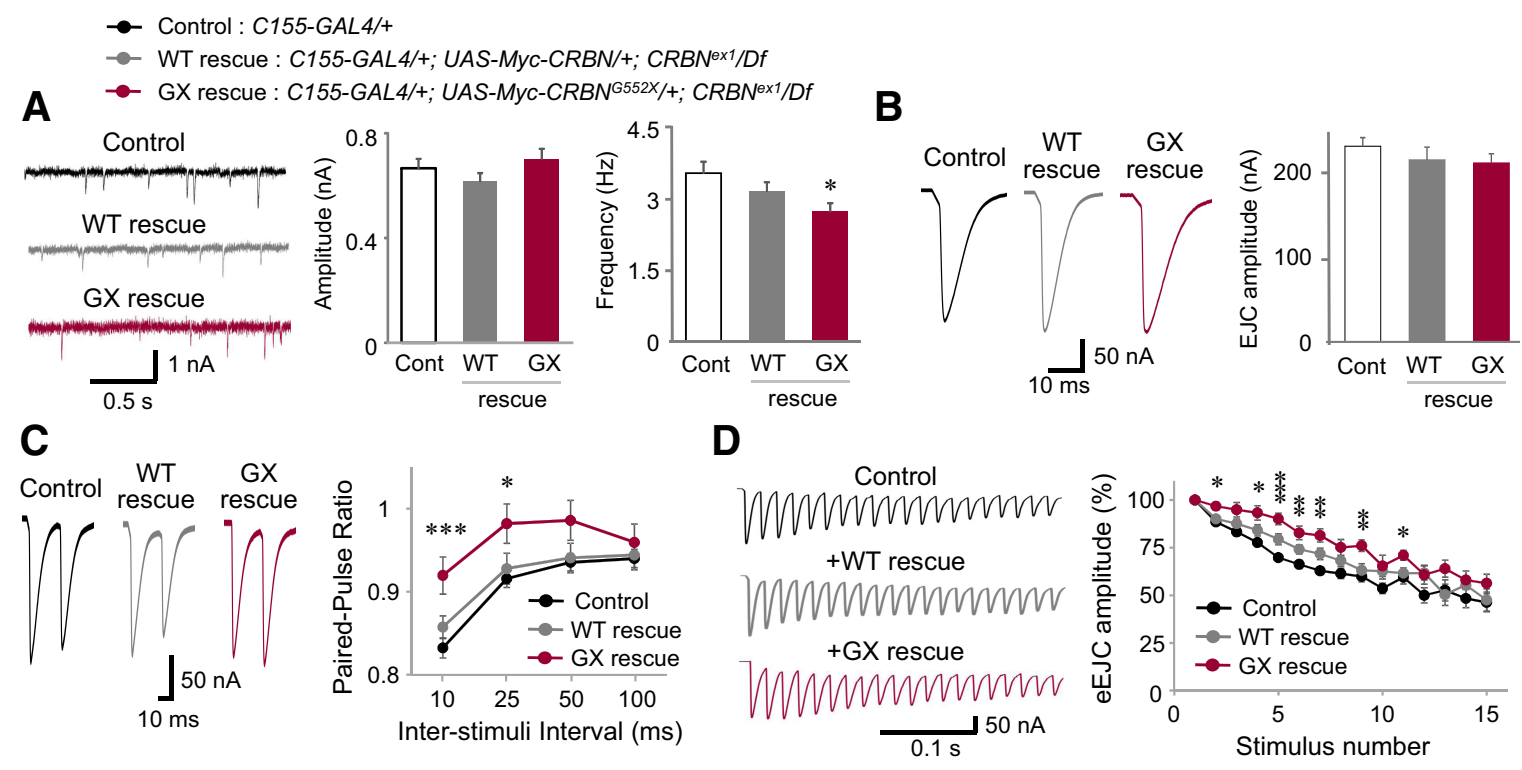

Figure 6. Decreased probability of neurotransmitter release in Drosophila Crbn mutants is not rescued by the overexpression of the pathogenic CRBN mutant. $A$, Representative traces (left) of spontaneous mEJCs in the following genotypes: (155-GAL4/+ (control), C155-GAL4/+; UAS-Myc-CRBN WT/+; CRBN ${ }^{\text {ex1 }} /$ Df (CRBN WT rescue) and C155-GAL4/+; UAS-Myc-CRBN ${ }^{\text {G552X } /+ \text {; }}$ CRBN ${ }^{\mathrm{ex} 1} / D f$ (CRBN GX rescue). Mean amplitude (middle) and frequency (right) of spontaneous mEJCs are shown. $n=11$ control; $n=8$ CRBN-WT rescue; $n=18$ CRBN-GX rescue. $\boldsymbol{B}$, Representative eEJC traces (left) and mean amplitude of eEJCs (right) in CRBN rescue animals. $n=11$ control; $n=8$ CRBN-WT rescue; $n=18$ CRBN-GX rescue. C, Overexpression of CRBN WT rescued the increased PPR (10 and $25 \mathrm{~ms} \mathrm{ISI)} \mathrm{at} \mathrm{Crbn} \mathrm{mutant} \mathrm{synapses} \mathrm{but} \mathrm{CRBN} \mathrm{GX} \mathrm{did} \mathrm{not.} \mathrm{Representative} \mathrm{traces} \mathrm{(left)} \mathrm{and} \mathrm{PPR} \mathrm{is} \mathrm{plotted} \mathrm{against} \mathrm{indicated} \mathrm{ISIs} \mathrm{(right).} n=11$ control; $n=8$ CRBN-WT rescue; $n=18$ CRBN-GX rescue. D, 20-pulse train stimulation-induced STP at Crbn mutant synapses is rescued by presynaptic CRBN-WT expression but not by CRBN-GX. Representative traces (left) and the amplitudes of eEJCs are plotted against stimulus number (right). $n=10$ control; $n=8$ CRBN-WT rescue; $n=15$ CRBN-GX rescue. All data shown are mean \pm SEM. ${ }^{* * *} p<0.001 ;{ }^{* *} p<0.01 ;{ }^{*} p<$ 0.05. n.s., Not significant by independent Student's $t$ test.

probability of release (Pr) from CRBN-lacking presynaptic excitatory neurons. We confirmed decreased Pr in excitatory (Fig. 4C; $p<0.05$ at the second $\sim 20^{\text {th }}$ stimulus) but not inhibitory synapses (Fig. $4 D ; p>0.05$ at the second $\sim 20^{\text {th }}$ stimulus) with altered shortterm plasticity (STP) induced by 20 -pulse train stimulation. The results suggest that cognitive impairment in $\mathrm{Crbn} \mathrm{KO}$ mice is caused by reduced presynaptic excitatory neurotransmitter release, not by alterations in long-term synaptic plasticity.

\section{Drosophila Crbn loss-of-function mutants show decreased probability of neurotransmission release not rescued by the overexpression of the CRBN G552X mutant}

Crbn KO mice showed decreased neurotransmitter Pr in excitatory synapses without detectable structural phenotypes. We confirmed the changes in excitatory Pr in other species by testing CRBN function in third-instar NMJ synapses in Drosophila (Fig. 5A), which are glutamatergic excitatory synapses (Davis and Müller, 2015). The trans-heterozygous loss-of-function mutants, $C R B N^{\text {exl }} / D f$, bear a copy of the $C R B N^{\text {ex1 }}$ allele and a deficiency $(D f)$ allele for Drosophila Crbn (CG3925) (Fig. 5B-D). CRB$N^{\text {exl }} / D f$ mutants showed normal synaptic structures similar to those observed in WT and Crbn KO neurons (Fig. 5E). We observed normal amplitude $\left(t_{(25)}=-1.652, p=0.11\right)$ and normal frequency $\left(t_{(25)}=-1.975, p=0.062\right)$ of the miniature excitatory junctional currents (mEJCs) (Fig. $5 F$ ), and normal amplitude of the evoked EJCs (eEJCs, Fig. $5 G ; t_{(25)}=0.553 ; p=0.58$ ) in $C R B N^{\text {exl }} / D f$ mutants. Notably, $C R B N^{\text {exl }} / D f$ mutants had obviously increased PPR (Fig. $5 H$; ISI at $10 \mathrm{~ms}: t_{(24)}=-4.935, p<$ 0.001 ; ISI at $25 \mathrm{~ms}: t_{(24)}=-4.604, p<0.001$; ISI at $50 \mathrm{~ms}: t_{(24)}=$ $-4.730, p<0.001$; ISI at $\left.100 \mathrm{~ms}: t_{(24)}=-4.614, p<0.001\right)$ and altered 20-pulse train stimulation-induced STP (Fig. 5I; $p<$ 0.001 at the third $\sim$ sixth stimulus; $p<0.01$ at the seventh stimulus; $p<0.05$ at eighth $\sim 10^{\text {th }}$ stimuli). These Drosophila results were highly consistent with the presynaptic neurotransmitter release phenotypes seen in Crbn KO mice.

Next, we evaluated whether impaired presynaptic release could be rescued by the reintroduction of WT CRBN. Using a pan-neuronal C155-GAL4 driver and UAS-Crbn lines, we specifically overexpressed WT CRBN in neurons with a $C R B N^{\mathrm{ex} 1} / D f$ background (C155-GAL4/+; UAS-Myc-CRBN/+;CRBN ${ }^{\mathrm{ex} 1} / D f$ ) and tested presynaptic release phenotypes. The overexpression of not only WT CRBN, but also the Drosophila CRBN G552X mutant did not affect the amplitudes of mEJCs (Fig. 6A; amplitude: $F_{(2,34)}=1.056, p=0.359$ ) or eEJCs (Fig. $6 B$; amplitude: $F_{(2,34)}=$ $0.767, p=0.473$ ) but mEJC frequency in the overexpression of CRBN G552X mutant was decreased (Fig. 6A; frequency: $\left.F_{(2,34)}=4.264, p=0.022\right)$. However, the overexpression of WT CRBN successfully rescued PPR (Fig. 6C; ISI at $10 \mathrm{~ms}$ : $F_{(2,34)}=6.637, p=0.004$; ISI at $25 \mathrm{~ms}: F_{(2,34)}=4.055, p=$ 0.026 ; ISI at $50 \mathrm{~ms}: F_{(2,34)}=2.474, p=0.099$; ISI at $100 \mathrm{~ms}$ : $\left.F_{(2,33)}=0.493, p=0.614\right)$, and 20 -pulse train stimulationinduced STP (Fig. $6 D ; p<0.001$ at the fifth stimulus, $p<0.01$ at the sixth, seventh, and ninth stimulus, $p<0.05$ at the second, fourth, and $11^{\text {th }}$ stimulus, $p>0.05$ at the third, eighth, $10^{\text {th }}$, and $12^{\text {th }} \sim 15^{\text {th }}$ stimulus) in $C R B N^{\text {exl }} / D f$ mutants to the levels seen in C155-GAL4 control flies. These rescue effects were not found in flies overexpressing the Drosophila CRBN G552X mutant, which mimics the human CRBN R419X pathogenic mutant (Fig. 6C,D). Together, these results strongly suggest that the presynaptic functions of CRBN are highly conserved from flies to humans and that presynaptic defects are caused not only by lack of Crbn expression, but also by the CRBN nonsense mutation that is observed in human mild intellectual disability patients (Higgins et al., 2004, 2008). 

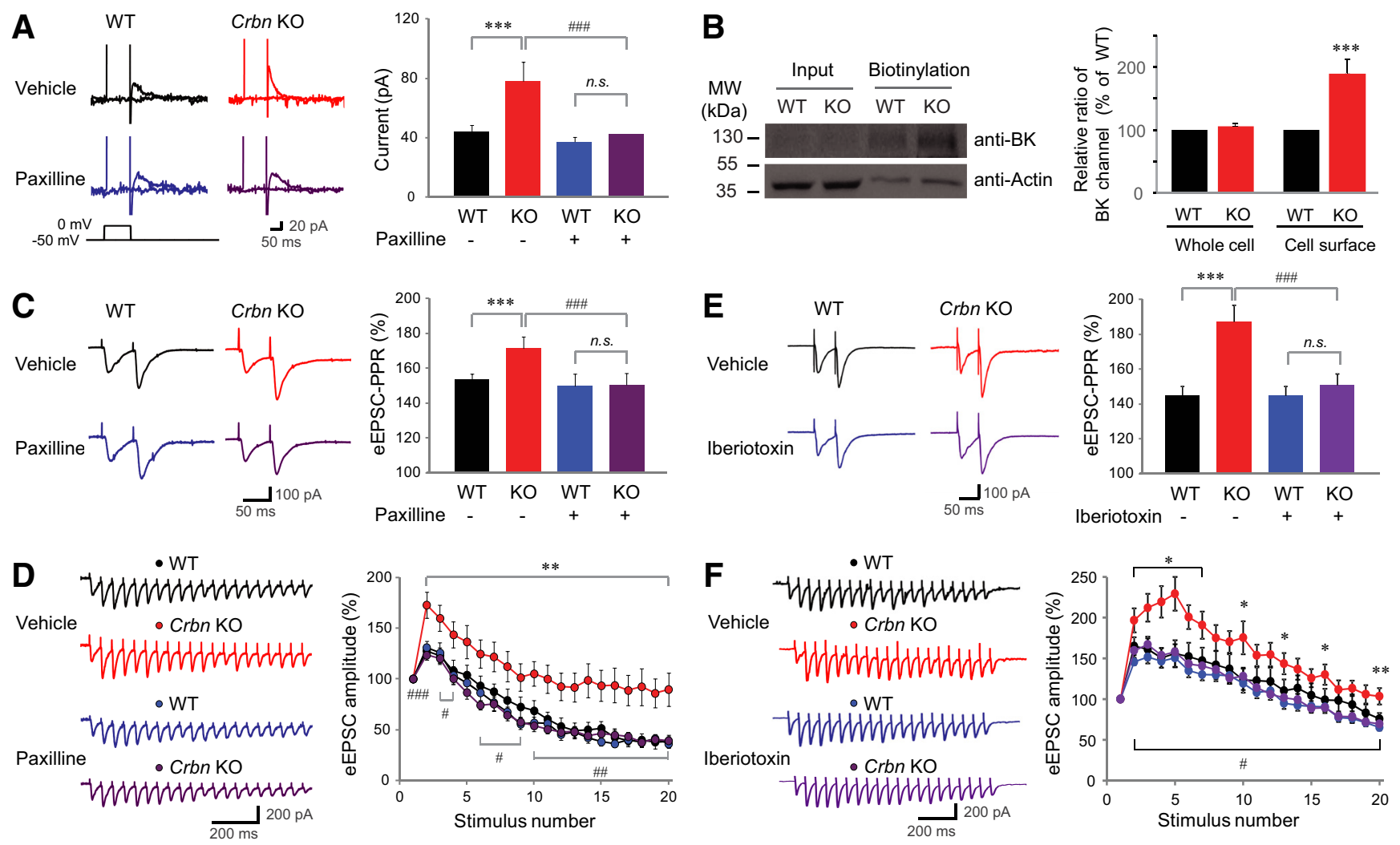

Figure 7. Reduced excitatory presynaptic function in C $r b n \mathrm{KO}$ mice is rescued by a BK channel blocker. $A$, Increased $I_{\mathrm{K}(\mathrm{Ca})}$ in hippocampal CA1 pyramidal neurons in Crbn K0 mice were selectively reduced by paxilline (a pan-BK channel blocker, $10 \mu \mathrm{m}$ ). $n=29,3$ (29 cells from 3 animals) for WT mice with vehicle (WT + vehicle); $n=17,3$ for K0 mice with vehicle (K0 + vehicle); $n=29$, 3 (WT + paxilline); $n=29,3$ (KO + paxilline). $\boldsymbol{B}$, Increased surface expression of BK channels in Crbn K0 mice. Hippocampal slices prepared from WT and Crbn K0 mice were used for steady-state biotinylation of surface BK channels. Input (10\%) of total lysates are shown on the left and the biotinylated surface BK channels are shown on the right. Actin was used as a control. Quantification of surface BK channel levels in WT and Crbn KO mice. Data are normalized to WT and presented as mean \pm SEM. $n=4,{ }^{* *} p<0.01$ (on independent Student's $t$ test). C, Paxilline (10 $\mu \mathrm{m}$ ) negates the increased PPR (50 ms inter stimulus interval) at Crbn KOSC-CA1 synapses. $n=15,3$ WT + vehicle; $n=16,3 \mathrm{KO}+$ vehicle; $n=14,3 \mathrm{WT}+$ paxilline; $n=16,3 \mathrm{KO}+$ paxilline. $\boldsymbol{D}$, Paxilline $(10 \mu \mathrm{M}$ ) restores increased activity-dependent plasticity during repetitive stimulation (20 pulses at $20 \mathrm{~Hz}$ ) at Crbn KOSC-CA1 synapses. $n=20,5 \mathrm{WT}+$ vehicle; $n=16,6 \mathrm{KO}+$ vehicle; $n=13$, 3 WT + paxilline; $n=11,3 \mathrm{KO}+$ paxilline. E, Iberiotoxin ( $100 \mathrm{~nm}$ ) negates the increased PPR ( $50 \mathrm{~ms}$ interstimulus interval) at Crbn KOSC-CA1 synapses. $n=12,2 \mathrm{WT}+$ vehicle; $n=14,2 \mathrm{KO}+$ vehicle; $n=18,2 \mathrm{WT}+$ iberiotoxin; $n=17,2 \mathrm{KO}+$ iberiotoxin. $\boldsymbol{F}$, Iberiotoxin $(100 \mathrm{nM}$ ) restores increased activity-dependent plasticity during repetitive stimulation (20 pulses at $20 \mathrm{~Hz}$ ) at $(\mathrm{rbn}$ KO SC-CA1 synapses. $n=14,2 \mathrm{WT}+$ vehicle; $n=16,2 \mathrm{KO}+$ vehicle; $n=18,2 \mathrm{WT}+$ iberiotoxin; $n=21,2 \mathrm{KO}+$ iberiotoxin; ${ }^{*} p<0.05 ;{ }^{* * *} p<0.001$ or \#\#\#p $<0.001$.

Table 1. Comparison of the intrinsic properties of hippocampal CA1 pyramidal neurons from WT and Crbn KO mice

\begin{tabular}{llll}
\hline & $C_{\mathrm{m}}(\mathrm{pF})$ & $R_{\text {in }}(\mathrm{M} \Omega)$ & $\mathrm{RMP}(\mathrm{mV})$ \\
\hline WT + vehicle & $44.65 \pm 1.35$ & $133.63 \pm 7.16$ & $-73.42 \pm 0.57$ \\
WT + paxilline & $44.33 \pm 1.40$ & $134.39 \pm 5.33$ & $-73.25 \pm 0.72$ \\
K0 + vehicle & $44.63 \pm 1.33$ & $127.65 \pm 4.38$ & $-73.82 \pm 0.91$ \\
K0 + paxilline & $45.89 \pm 2.44$ & $125.14 \pm 5.34$ & $-73.25 \pm 0.70$ \\
\hline
\end{tabular}

Whole-cell capacitance $\left(C_{\mathrm{m}}\right)$, resting input resistance $\left(R_{\text {in }}\right)$, and resting membrane potential (RMP) were measured in current-clamp mode. All data shown are mean \pm SEM and all statistical differences in this figure were calculated as not significant by independent Student's $t$ test.

Crbn KO mice show increased BK channel activity-induced synaptic and behavioral dysfunction

Since a previous report in which we established that CRBN binds to the $\mathrm{C}$ terminus of the BK channel $\alpha$ subunit and inhibits surface expression of the BK channel (Jo et al., 2005), an interaction between CRL4 ${ }^{\text {CRBN }}$ and the BK channel, which promotes ubiquitination of the BK channel and blocks membrane exposure via ER retention of the BK channel, has been reported (Liu et al., 2014). Therefore, we hypothesized that a Pr decrease in Crbn KO mice might be due to BK channel hyperactivity. We measured calcium-activated potassium currents $\left(I_{\mathrm{K}(\mathrm{Ca})}\right)$ by applying brief depolarization from the holding potential $(-50 \mathrm{mV})$ under a TTX-including external solution (Aoki and Baraban, 2000). As a result, Crbn KO mice showed approximately twofold higher $I_{\mathrm{K}(\mathrm{Ca})}$ than WT mice, but treatment with $10 \mu \mathrm{M}$ paxilline, a BK channel blocker, in Crbn $\mathrm{KO}$ mice normalized $I_{\mathrm{K}(\mathrm{Ca})}$ to the extent that it became similar to the current in neurons from WT mice (Fig. $7 A$; genotype: $F_{(1,94)}=12.931, p<0.001$; treatment: $F_{(1,94)}=$ 14.585, $p<0.001$; genotype $\times$ treatment: $F_{(1,94)}=6.580, p=$ 0.012 ). This suggests that BK channel activity is significantly increased in Crbn KO mice. To test the idea, we measured BK channel expression in the plasma membrane. We analyzed the amount of actin for control as well. We found that the expression of the BK channel in the plasma membrane was increased in Crbn KO mice (Fig. $7 B$; Input: $p=0.099$; Biotinylation: $p=0.006$ ), suggesting that increased $\mathrm{BK}$ current in Crbn $\mathrm{KO}$ is due to increased BK channel expression in the plasma membrane. We next tested whether increased BK channel activity in Crbn KO mice induces excitatory $\operatorname{Pr}$ changes. Paxilline eliminated the increase in PPR (Fig. $7 C$; genotype: $F_{(1,46)}=9.152, p=0.004$; treatment: $F_{(1,46)}=14.677, p<0.001$; genotype $\times$ treatment: $F_{(1,46)}=$ $6.202, p=0.016)$ and 20-pulse train stimulation-induced responses observed in Crbn KO mice and established similar levels to those seen in WT mice (Fig. $7 D ; p<0.01$ at all responses to the second $\sim 20^{\text {th }}$ stimulus between $\mathrm{WT}+$ vehicle vs $\mathrm{KO}+$ vehicle, $p<0.05$ at all responses to the second $\sim 20^{\text {th }}$ stimulus between $\mathrm{KO}+$ vehicle vs $\mathrm{KO}+$ paxilline). We found that paxilline treat- 

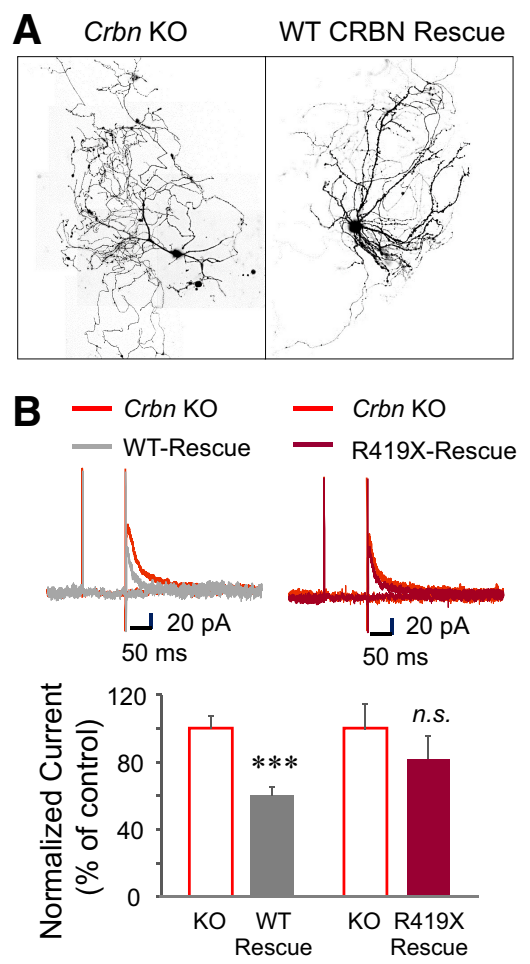
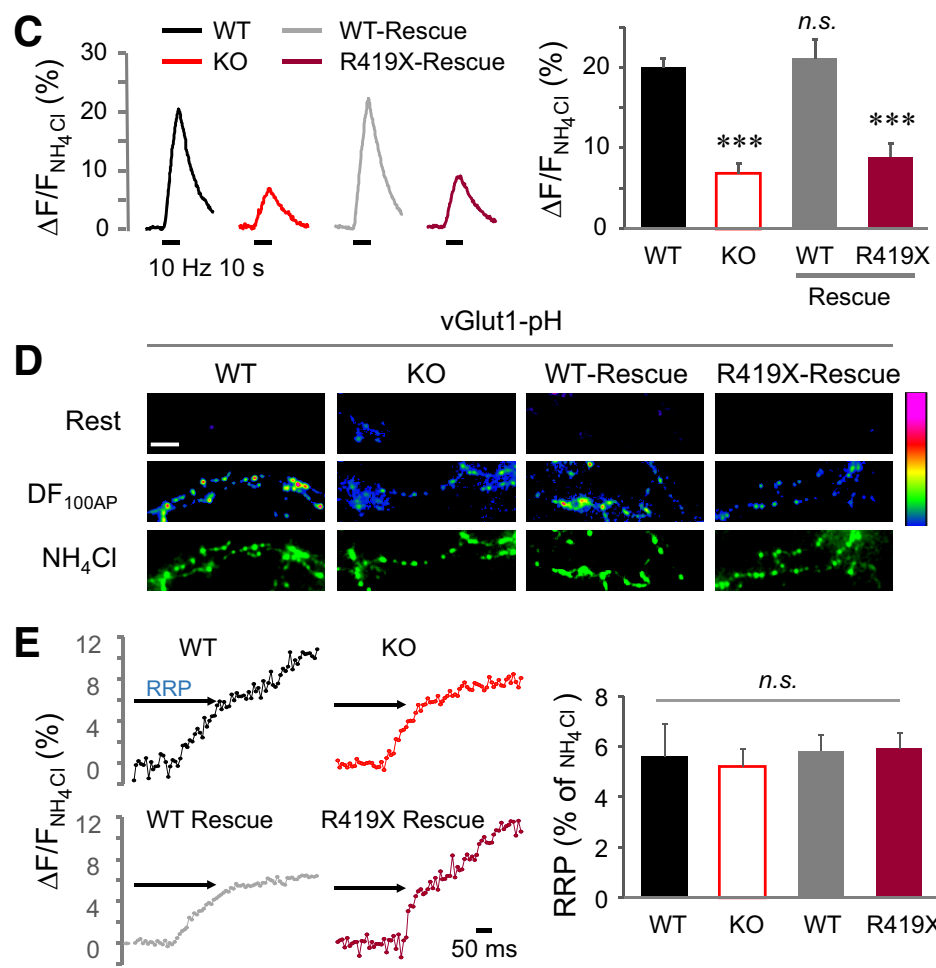

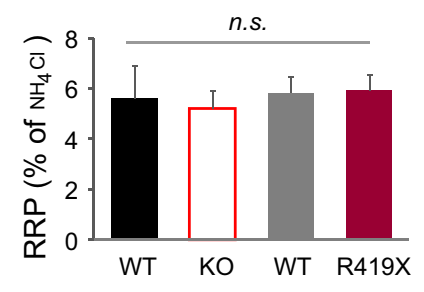

Figure 8. Human R419X CRBN expression rescue decreased the probability of release in Crbn K0 mice. A, Representative images of WT and Crbn K0 neurons. Primary cultured hippocampal neurons were transfected with cytosol GFP (EGFP only) and fixed 14 20 DIV. B, Representative $I_{\mathrm{K}(\mathrm{Ca})}$ traces in untransfected (black) and transfected (red) hippocampal neurons cultured from Crbn $\mathrm{KO}$ mice. Overexpression of CRBN WT reduced the increased $I_{\mathrm{K}(\mathrm{Ca})}$ in hippocampal cultured neurons in Crbn K0 mice but overexpression of CRBN R419X did not. $n=11$ untransfected Crbn K0 cells; $n=9$ WT CRBN transfected Crbn KO cells (WT-Rescue); $n=11$ untransfected Crbn KO cells; $n=10$ R419X CRBN transfected Crbn K0 cells (R419X-Rescue). C, Left, Representative traces of vG-pH response to $100 \mathrm{AP}$ stimuli from WT, (rbn K0, WT-Rescue, and R419X-Rescue neurons (normalized to the NH $\mathrm{Nl}_{4}$ peak signal). Right, Mean value of $100 \mathrm{AP}$ response from WT ( $n=8$ cells), $(r b n$ K0 ( $n=8$ cells), WT-Rescue ( $n=7$ cells), and R419X-Rescue ( $n=7$ cells). ${ }^{* * *} p<0.001$. D, Representative fields of vG-pH fluorescence images at rest, $\Delta$ F100, and NH ${ }_{4}$ Cl application from WT, Crbn K0, WT-Rescue, and R419X-Rescue, respectively. $E$, Left, Representative traces of vG-pH response to $20 \mathrm{AP}$ stimuli at $100 \mathrm{~Hz}$ to discriminate readily releasable pool (RRP). The arrow indicates a short plateau representing RRP position (Ariel and Ryan, 2010). Right, Mean RRP size from WT (5.64 $\pm 1.28 ; n=7$ cells), (rbn K0 (5.23 $\pm 0.68 ; n=6$ cells), WT-Rescue (5.84 $\pm 0.64 ; n=7$ cells), and R419X-Rescue (5.94 $\pm 0.61 ; n=7$ cells).

ment itself did not changes intrinsic properties such as membrane capacitance, input resistance, and resting membrane potential in hippocampal CA1 pyramidal neurons in either WT or Crbn KO mice (Table 1). We confirmed our findings with iberiotoxin, another BK channel blocker. Our results clearly showed that iberiotoxin decreased PPR elevation in Crbn $\mathrm{KO}$ (Fig. 7E; genotype: $F_{(1,57)}=$ 12.321, $p<0.001$; treatment: $F_{(1,57)}=7.045, p=0.010$; genotype $\times$ treatment: $\left.F_{(1,57)}=6.896, p=0.011\right)$ and 20-pulse train stimulation-induced responses (Fig. $7 F ; p<0.05$ at all responses to the second $\sim$ seventh, $10^{\text {th }}, 13^{\text {th }}, 16^{\text {th }}$, and $20^{\text {th }}$ stimulus between $\mathrm{WT}+$ vehicle vs $\mathrm{KO}+$ vehicle, $p<0.05$ at all responses to the second $\sim 20^{\text {th }}$ stimulus between $\mathrm{KO}+$ vehicle vs $\mathrm{KO}+$ iberiotoxin).

\section{Human mutant form of Crbn, R419X, results in decreased probability of neurotransmission}

Next, we tested the synaptic effects of the intellectual disabilityrelated human mutant form of CRBN, R419X. For this purpose, we cultured hippocampal neurons from $\mathrm{Crbn} \mathrm{KO}$ and overexpressed R419X mutant CRBN or WT CRBN and then measured spine morphology, BK channel activity, and probability of neurotransmitter release. First, overexpression of R419X mutant CRBN and WT CRBN did not induce detectable changes in neuronal structure (Fig. 8A). However, the BK channel activity of Crbn KO neurons with WT CRBN expression was significantly lower than that of the untransfected control neurons from Crbn KO mice, whereas Crbn KO neurons with R419X mutant CRBN expression showed a relatively small decrease in BK channel activity (Fig. $8 B$; WT rescue, $t_{(18)}=4.215, p<0.001$; $\mathrm{R} 419 \mathrm{X}$ rescue, $\left.t_{(19)}=0.869, p=0.396\right)$. This suggests that increased BK channel activity in Crbn KO neurons was reduced by WT CRBN expression, but not by R419X mutant CRBN expression. Next, we tested the influence of the R419X mutant on release probability in Crbn KO hippocampal neurons. To measure synaptic transmission at presynaptic terminals directly, we used a high-fidelity optical imaging system combined with vG-pH assay in primary cultured hippocampal neurons. We monitored $\mathrm{vG}-\mathrm{pH}$ responses of hippocampal neurons to 100 action potential (AP) at $10 \mathrm{~Hz}$ in WT and Crbn KO neurons. The release probability in Crbn KO neurons was significantly suppressed compared with WT neurons $\left([100 \mathrm{AP}]_{\mathrm{WT}}=20.07 \pm 1.02,[100 \mathrm{AP}]_{\mathrm{Crbn} \mathrm{\textrm { } \mathrm { KO }}}=6.89 \pm 1.32\right)$. This defect was completed restored by reexpressing Crbn WT cDNA in Crbn KO neurons ([100AP $\left.]_{\text {resWT in Crbn KO }}=21.17 \pm 2.44\right)$. In addition, neurons with R419X mutant CRBN expression failed to exhibit release probability recovery to the level of WT $\left([100 \mathrm{AP}]_{\text {resR419X in } \mathrm{Crbn} \mathrm{KO}}=8.95 \pm 1.72\right)$, suggesting that CRBN is indeed involved in presynaptic excitatory neurotransmitter release (Fig. 8C; $F_{(3,26)}=20.19, p<0.001$ ). Interestingly, the size of readily releasable pool (RRP) among the four different conditions (WT, Crbn KO, CRBN WT rescue, CRBN R419X rescue) was indistinguishable (Fig. $8 E ; F_{(3,23)}=0.126, p=0.944$ ), implying that CRBN does not control RRP size. 


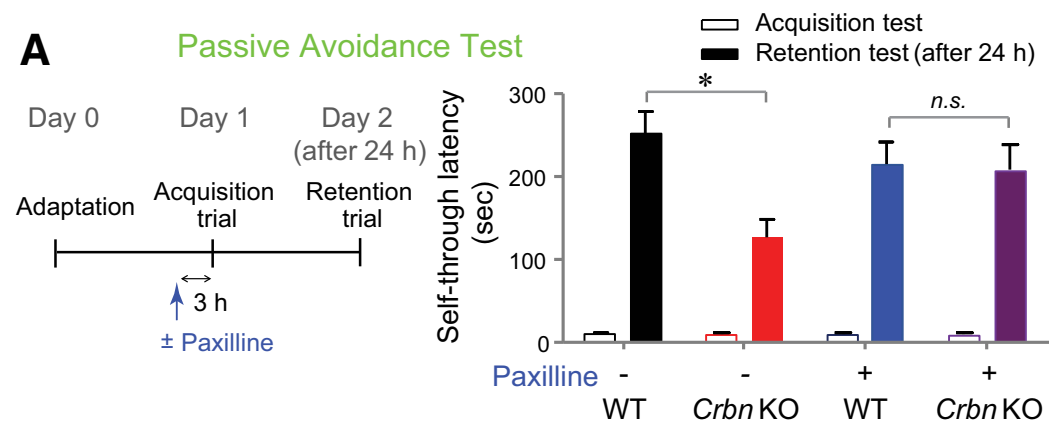

B Novel Object Recognition Test
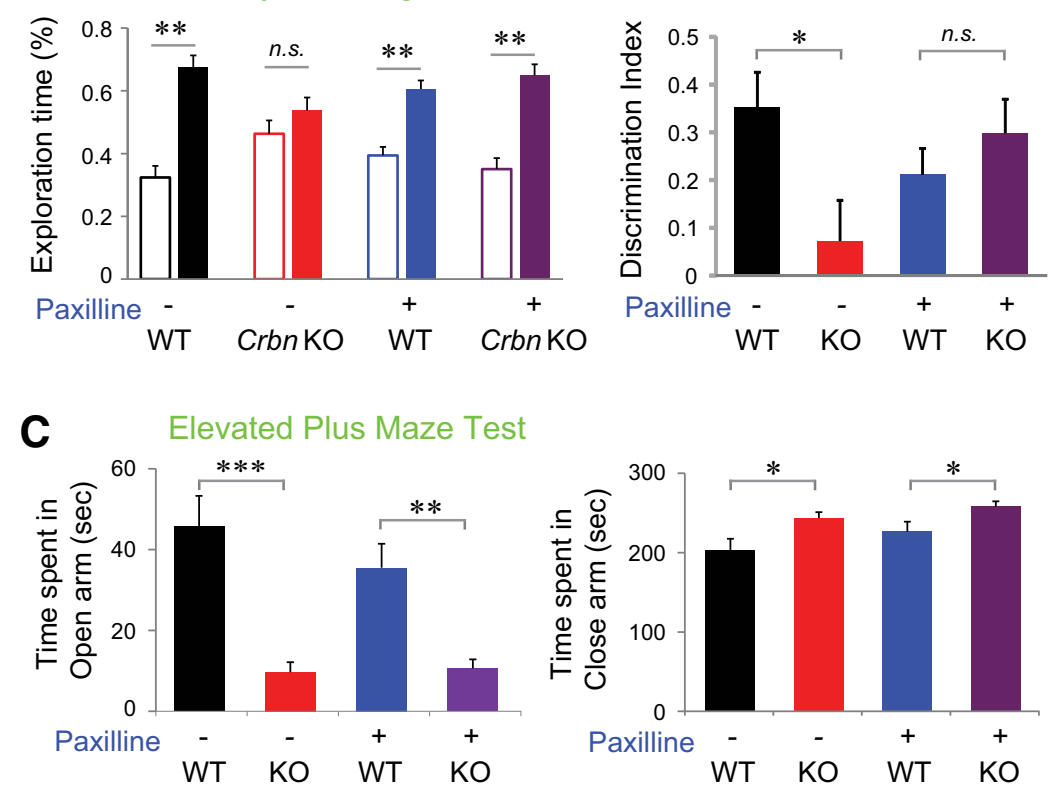

Figure 9. Paxilline treatment rescued abnormal cognitive behaviors in $\mathrm{Crbn} \mathrm{KO}$ mice. A, Paxilline treatment rescued the abnormal behavior of $\mathrm{Cr} b \mathrm{~K}$ KO mice in the passive avoidance test. $n=7$ WT with vehicle; $n=6 \mathrm{~K} 0$ with vehicle; $n=7$ WT with paxilline; $n=6 \mathrm{KO}$ with paxilline. $\boldsymbol{B}$, Paxilline treatment rescued the abnormal behavior of $\mathrm{Crbn} \mathrm{KO}$ mice in the novel object recognition test. Left, Exploration time. Right, Discrimination index. $n=8$ WT with vehicle; $n=8 \mathrm{KO}$ with vehicle; $n=8$ WT with paxilline; $n=$ $8 \mathrm{KO}$ with paxilline. C, Paxilline treatment did not affect the hyperanxious behavior of $\mathrm{Crbn} \mathrm{KO}$ mice in the EPM test. Left, Time spent in the open arm. Right, Time spent in the closed arm. $n=9$ WT with vehicle; $n=9 \mathrm{KO}$ with vehicle; $n=8$ WT with paxilline; $n=$ $8 \mathrm{KO}$ with paxilline. All data are presented as mean \pm SEM. ${ }^{* * *} p<0.001,{ }^{* *} p<0.01,{ }^{*} p<0.05$, n.S., not significant for comparisons within genotype; n.S., not significant for comparisons within treatment by two-way ANOVA with Holm-Sidak's multiple-comparisons test.

\section{Paxilline restored impaired cognitive behavior in Crbn KO mice}

Finally, we investigated whether behavioral defects in Crbn $\mathrm{KO}$ mice could be restored by treatment with the BK blocker paxilline. We found that paxilline treatment rescued the abnormal context-dependent associative memory of Crbn $\mathrm{KO}$ mice, as measured by the passive avoidance test (Fig. 9A). We also observed that Crbn KO mice showed less preference for new objects, as calculated by exploration time (WT_Vehicle, $t_{(7)}=4.778, p=$ 0.002 ; KO_Vehicle, $t_{(7)}=0.871, p=0.413$; WT_Paxilline, $t_{(7)}=$ 3.883, $p=0.006$; KO_Paxilline, $\left.t_{(7)}=4.244, p=0.004\right)$ and discrimination index (vehicle, $t_{(14)}=2.492, p=0.026$; Paxilline, $\left.t_{(14)}=0.980, p=0.344\right)$, and paxilline treatment successfully reversed this defect (Fig. 9B). Interestingly, Crbn KO mice showed hyperanxious behavior in the EPM test (time spent in open arm: vehicle, $t_{(16)}=4.485, p<0.001$; paxilline, $t_{(14)}=3.924, p=$ 0.001 ; time spent in close arm: vehicle, $t_{(16)}=2.529, p=0.022$; paxilline, $\left.t_{(14)}=2.194, p=0.046\right)$, a behavior that paxilline did not affect (Fig. 9C). Our results strongly suggested that $\mathrm{Crbn} \mathrm{KO}$ mice exhibit abnormally increased BK channel activity-induced decreased excitatory presynaptic release, which is closely related to cognitive dysfunction.

\section{Discussion}

In this study, we found that CRBN mutation induces intellectual disability by inducing hyperfunction of BK channels and subsequent decreases in presynaptic neurotransmitter release. CRBNmediated modulation of $\mathrm{BK}$ channel activity has been reported in primary cultured neurons in previous studies on CRBN function (Jo et al., 2005; Liu et al., 2014). However, although the CRBN-BK channel interaction was expected to affect cognitive function, no direct evidence was available at the synaptic or behavioral levels. Our study of synapses in ex vivo brain slices from a Crbn-KO animal model provided evidence for the cellular and molecular mechanism of synaptic dysfunction in Crbn $\mathrm{KO}$ animals. Our results demonstrated that BK channel expression in the plasma membrane is elevated in Crbn $\mathrm{KO}$ mice, resulting in BK channel hyperfunction and subsequent reduction of presynaptic release. The RRP results indicated that the loss of function of CRBN does not affect the presynaptic machinery involved in the maintenance of synaptic pools. Furthermore, the evidence in support of this BK channel mechanism as a causal contributor to cognitive deficits in the Crbn $\mathrm{KO}$ mice was strengthened by the successful rescue of both synaptic and cognitive deficits upon administration of a BK channel blocker.

The role of $\mathrm{K}^{+}$channels in synaptic and cognitive function has garnered wide interest (Lee and Jan, 2012). In particular, $\mathrm{Ca}^{2+}$-activated $\mathrm{K}^{+}$channels are typical $\mathrm{K}^{+}$channels that modulate the regulation and maintenance of neuronal function. In particular, altered BK channel activity has recently been suggested to cause cognitive impairment. For instance, human patients with FMR1 missense mutations and Fmr1 KO animals show decreased BK channel activity and increased presynaptic neurotransmitter release (Deng et al., 2013; Myrick et al., 2015). Genetic upregulation of BK channel activity also recovered neuronal and synaptic defects induced by FMRP loss in mice (Deng and Klyachko, 2016). In contrast, we found that $\mathrm{Crbn} \mathrm{KO}$ mice exhibited increased BK channel activity and a subsequent decrease in excitatory $\mathrm{Pr}$, whereas a BK channel blocker normalized synaptic and behavioral function in Crbn KO mice. Therefore, our results suggest that balanced BK channel activity is critical for synaptic and cognitive function. Further studies are required to determine whether hyperactivity of the BK channel causes intellectual disability. To date, no cognitive defects have been reported from a human harboring gain-of-functional mutations in the BK channel (Du et al., 2005; Li et al., 2018). However, it should be noted that such mutations accompanied increased $\mathrm{Ca}^{2+}$ sensitivity 
(D434G mutation) (Du et al., 2005) or increased open channel duration and probability (N995S mutation) (Li et al., 2018), which might be different from the changes caused by elevated expression of the native BK channel. It will be interesting to investigate thoroughly the functional and behavioral consequences caused by specific mutations that change BK channel characteristics. Nonetheless, based on the findings of BK channel hyperfunction in $\mathrm{Crbn} \mathrm{KO}$ animals, our study provides a possible therapeutic strategy for ameliorating CRBN-related intellectual disability.

One of the concerns regarding experiments conducted with conventional or conditional Crbn KO mice is whether the complete genetic deletion of the gene encoding CRBN in Crbn $\mathrm{KO}$ mice is a valid model of CRBN-associated intellectual disability in human patients. To address this question, we applied two approaches. First we used a Drosophila model with neuron-specific Crbn overexpression in Crbn KO flies using both WT and G552X mutant CRBN. Drosophila CRBN G552X mutation mimics the human CRBN R419X mutation, which causes mild intellectual disability. We first confirmed that presynaptic release defects were exhibited in $C r b n \mathrm{KO}$ flies $\left(C R B N^{\mathrm{ex} 1} / D f\right)$. In addition, the defects were rescued by reintroduction of WT CRBN into Crbn KO flies, but not by reintroduction of the G552X mutant CRBN. We also used cultured hippocampal neurons from $\mathrm{Crbn} \mathrm{KO}$ mice expressing human WT or R419X mutant CRBN to demonstrate that the reduced $\mathrm{Pr}$ in Crbn $\mathrm{KO}$ neurons is restored by reintroduction of WT CRBN, but not by R419X mutant CRBN. These results suggest that presynaptic Pr decrease can be induced by either complete loss of CRBN expression or CRBN mutation (i.e., R419X in humans and G552X in Drosophila).

There are some conflicting points between previous studies and our results. Crbn forebrain-specific conditional $\mathrm{KO}$ mice showed impaired learning and memory but normal anxiety-like behavior (Rajadhyaksha et al., 2012). In this study, we observed that $\mathrm{Crbn} \mathrm{KO}$ mice have cognitive defects with hyperanxious behavior (Fig. 9). Interestingly, the BK channel blocker rescued altered behaviors in the passive avoidance test and a novel object recognition test, but did not affect hyperanxious behavior. We suspect that this dissimilarity originates from the different CRBN expression pattern in the brains of different mouse models. For example, CRBN is still expressed in the cerebellum in Crbn forebrain-specific conditioned KO mice (Rajadhyaksha et al., 2012) and the cerebellum is important to not only motor but also mood behavior (Phillips et al., 2015). Our results suggest that the CRBN mutation effect in those anxiety-related brain regions is due to a $\mathrm{BK}$ channel-independent mechanism. It is not yet clear whether $C R B N$-mutated human intellectual disability patients show anxiety disorders, but mood disorders in intellectual disability are an important issue (Hurley, 2006). Further investigation is needed to understand other defective phenotypes in $\mathrm{Crbn} \mathrm{KO}$ mice and $C R B N$-mutated human intellectual disability patients beyond cognitive issues. Another conflict is from our results of low BK channels activity in hippocampus from WT mice. We found that BK channel blockers paxilline and iberiotoxin did not affect calcium-activated potassium currents in CA1 pyramidal neurons or PPR and $20 \mathrm{~Hz}$ train responses in hippocampal SC-CA1 synapses of WT mice. We assumed that one of main reasons is the expression pattern of BK channel in the hippocampus. Immunostaining studies showed that $\alpha$ subunit of BK channels detected by slo1 antibody were rarely expressed in CA1 regions, although mossy fiber axons from granule cells of dentate gyrus and stratum oriens containing basal dendrites from CA3 pyramidal neurons showed high levels of expression of BK channels in rat or mouse hippocampus (Misonou et al., 2006; Sailer et al., 2006).

Together, our results show that Crbn KO animals with cognitive deficits exhibit normal synaptic morphology and plasticity, but presynaptic dysfunction in glutamate release mediated by increased BK channel activity. A large body of recent work suggests that cognitive impairment is caused by synaptopathy (Bhakar et al., 2012; Wallace et al., 2012) and channelopathy (Guglielmi et al., 2015). Therefore, our study using a Crbn KO animal model that displayed all of these dysfunctions will contribute to future investigations of intellectual disability.

\section{References}

Aizawa M, Abe Y, Ito T, Handa H, Nawa H (2011) mRNA distribution of the thalidomide binding protein cereblon in adult mouse brain. Neurosci Res 69:343-347. CrossRef Medline

Aoki T, Baraban SC (2000) Properties of a calcium-activated $\mathrm{K}^{+}$current on interneurons in the developing rat hippocampus. J Neurophysiol 83: 3453-3461. CrossRef Medline

Ariel P, Ryan TA (2010) Optical mapping of release properties in synapses. Front Neural Circuits 4: pii: 18. CrossRef Medline

Bartlett JB, Dredge K, Dalgleish AG (2004) The evolution of thalidomide and its IMiD derivatives as anticancer agents. Nat Rev Cancer 4:314-322. CrossRef Medline

Bhakar AL, Dölen G, Bear MF (2012) The pathophysiology of fragile X (and what it teaches us about synapses). Annu Rev Neurosci 35:417-443. CrossRef Medline

Choi TY, Jung S, Nah J, Ko HY, Jo SH, Chung G, Park K, Jung YK, Choi SY (2015) Low levels of methyl $\beta$-cyclodextrin disrupt GluAl-dependent synaptic potentiation but not synaptic depression. J Neurochem 132: 276-285. CrossRef Medline

Clem RL, Huganir RL (2010) Calcium-permeable AMPA receptor dynamics mediate fear memory erasure. Science 330:1108-1112. CrossRef Medline

Davis GW, Müller M (2015) Homeostatic control of presynaptic neurotransmitter release. Annu Rev Physiol 77:251-270. CrossRef Medline

Deng PY, Rotman Z, Blundon JA, Cho Y, Cui J, Cavalli V, Zakharenko SS, Klyachko VA (2013) FMRP regulates neurotransmitter release and synaptic information transmission by modulating action potential duration via BK channels. Neuron 77:696-711. CrossRef Medline

Deng PY, Klyachko VA (2016) Genetic upregulation of BK channel activity normalizes multiple synaptic and circuit defects in a mouse model of fragile X syndrome. J Physiol 594:83-97. CrossRef Medline

Dijkhuizen T, van Essen T, van der Vlies P, Verheij JB, Sikkema-Raddatz B, van der Veen AY, Gerssen-Schoorl KB, Buys CH, Kok K (2006) FISH and array-CGH analysis of a complex chromosome 3 aberration suggests that loss of CNTN4 and CRBN contributes to mental retardation in 3pter deletions. Am J Med Genet A 140:2482-2487. Medline

Du W, Bautista JF, Yang H, Diez-Sampedro A, You SA, Wang L, Kotagal P, Lüders HO, Shi J, Cui J, Richerson GB, Wang QK (2005) Calciumsensitive potassium channelopathy in human epilepsy and paroxysmal movement disorder. Nat Genet 37:733-738. CrossRef Medline

Feng Y, Ueda A, Wu CF (2004) A modified minimal hemolymph-like solution, HL3.1, for physiological recordings at the neuromuscular junctions of normal and mutant Drosophila larvae. J Neurogenet 18:377-402. CrossRef Medline

Fischer ES, Böhm K, Lydeard JR, Yang H, Stadler MB, Cavadini S, Nagel J, Serluca F, Acker V, Lingaraju GM, Tichkule RB, Schebesta M, Forrester WC, Schirle M, Hassiepen U, Ottl J, Hild M, Beckwith RE, Harper JW, Jenkins JL, Thomä NH (2014) Structure of the DDB1-CRBN E3 ubiquitin ligase in complex with thalidomide. Nature 512:49-53. CrossRef Medline

Gabriel LR, Wu S, Melikian HE (2014) Brain slice biotinylation: an ex vivo approach to measure region-specific plasma membrane protein trafficking in adult neurons. J Vis Exp 3:86. CrossRef Medline

Greenspan S, Woods GW (2014) Intellectual disability as a disorder of reasoning and judgement: the gradual move away from intelligence quotient-ceilings. Curr Opin Psychiatry 27:110-116. CrossRef Medline

Guglielmi L, Servettini I, Caramia M, Catacuzzeno L, Franciolini F, D’Adamo MC, Pessia M (2015) Update on the implication of potassium channels 
in autism: $\mathrm{K}^{+}$channel autism spectrum disorder. Front Cell Neurosci 9:34. CrossRef Medline

Higgins JJ, Pucilowska J, Lombardi RQ, Rooney JP (2004) A mutation in a novel ATP-dependent lon protease gene in a kindred with mild mental retardation. Neurology 63:1927-1931. CrossRef Medline

Higgins JJ, Hao J, Kosofsky BE, Rajadhyaksha AM (2008) Dysregulation of large-conductance $\mathrm{Ca}^{2+}$-activated $\mathrm{K}^{+}$channel expression in nonsyndromal mental retardation due to a cereblon p.R419X mutation. Neurogenetics 9:219-223. CrossRef Medline

Hohberger B, Enz R (2009) Cereblon is expressed in the retina and binds to voltage-gated chloride channels. FEBS Lett 583:633-637. CrossRef Medline

Hurley AD (2006) Mood disorders in intellectual disability. Curr Opin Psychiatry 19:465-469. CrossRef Medline

Ito T, Ando H, Suzuki T, Ogura T, Hotta K, Imamura Y, Yamaguchi Y, Handa H (2010) Identification of a primary target of thalidomide teratogenicity. Science 327:1345-1350. CrossRef Medline

Jo S, Lee KH, Song S, Jung YK, Park CS (2005) Identification and functional characterization of cereblon as a binding protein for large-conductance calcium-activated potassium channel in rat brain. J Neurochem 94:12121224. CrossRef Medline

Karr J, Vagin V, Chen K, Ganesan S, Olenkina O, Gvozdev V, Featherstone DE (2009) Regulation of glutamate receptor subunit availability by microRNAs. J Cell Biol 185:685-697. CrossRef Medline

Kasai H, Fukuda M, Watanabe S, Hayashi-Takagi A, Noguchi J (2010) Structural dynamics of dendritic spines in memory and cognition. Trends Neurosci 33:121-129. CrossRef Medline

Kim SH, Ryan TA (2013) Balance of calcineurin A $\alpha$ and CDK5 activities sets release probability at nerve terminals. J Neurosci 33:8937-8950. CrossRef Medline

Krönke J, Udeshi ND, Narla A, Grauman P, Hurst SN, McConkey M, Svinkina T, Heckl D, Comer E, Li X, Ciarlo C, Hartman E, Munshi N, Schenone M, Schreiber SL, Carr SA, Ebert BL (2014) Lenalidomide causes selective degradation of IKZF1 and IKZF3 in multiple myeloma cells. Science 343:301-305. CrossRef Medline

Krönke J, Fink EC, Hollenbach PW, MacBeth KJ, Hurst SN, Udeshi ND, Chamberlain PP, Mani DR, Man HW, Gandhi AK, Svinkina T, Schneider RK, McConkey M, Järås M, Griffiths E, Wetzler M, Bullinger L, Cathers BE, Carr SA, Chopra R, Ebert BL (2015) Lenalidomide induces ubiquitination and degradation of CK1 $\alpha$ in $\operatorname{del}(5 q)$ MDS. Nature 523:183-188. CrossRef Medline

Lee HY, Jan LY (2012) Fragile X syndrome: mechanistic insights and therapeutic avenues regarding the role of potassium channels. Curr Opin Neurobiol 22:887-894. CrossRef Medline

Lee KM, Jo S, Kim H, Lee J, Park CS (2011) Functional modulation of AMPactivated protein kinase by cereblon. Biochim Biophys Acta 1813:448455. CrossRef Medline

Lee KM, Yang SJ, Kim YD, Choi YD, Nam JH, Choi CS, Choi HS, Park CS (2013) Disruption of the cereblon gene enhances hepatic AMPK activity and prevents high-fat diet-induced obesity and insulin resistance in mice. Diabetes 62:1855-1864. CrossRef Medline

Lee SH, Kim YJ, Choi SY (2016) BMP signaling modulates the probability of neurotransmitter release and readily releasable pools in drosophila neuromuscular junction synapses. Biochem Biophys Res Commun 479:440446. CrossRef Medline

Li X, Poschmann S, Chen Q, Fazeli W, Oundjian NJ, Snoeijen-Schouwenaars FM, Fricke O, Kamsteeg EJ, Willemsen M, Wang QK (2018) De novo BK channel variant causes epilepsy by affecting voltage gating but not $\mathrm{Ca}^{2+}$ sensitivity. Eur J Hum Genet 26:220-229. CrossRef Medline

Liu J, Ye J, Zou X, Xu Z, Feng Y, Zou X, Chen Z, Li Y, Cang Y (2014) CRL4A(CRBN) E3 ubiquitin ligase restricts BK channel activity and prevents epileptogenesis. Nat Commun 5:3924. CrossRef Medline

Lu G, Middleton RE, Sun H, Naniong M, Ott CJ, Mitsiades CS, Wong KK, Bradner JE, Kaelin WG Jr (2014) The myeloma drug lenalidomide promotes the cereblon-dependent destruction of ikaros proteins. Science 343:305-309. CrossRef Medline

Millrine D, Kishimoto T (2017) A brighter side to thalidomide: its potential use in immunological disorders. Trends Mol Med 23:348-361. CrossRef Medline

Misonou H, Menegola M, Buchwalder L, Park EW, Meredith A, Rhodes KJ,
Aldrich RW, Trimmer JS (2006) Immunolocalization of the $\mathrm{Ca}^{2+}$ activated $\mathrm{K}^{+}$channel Slo1 in axons and nerve terminals of mammalian brain and cultured neurons. J Comp Neurol 496:289-302. CrossRef Medline

Myrick LK, Deng PY, Hashimoto H, Oh YM, Cho Y, Poidevin MJ, Suhl JA, Visootsak J, Cavalli V, Jin P, Cheng X, Warren ST, Klyachko VA (2015) Independent role for presynaptic FMRP revealed by an FMR1 missense mutation associated with intellectual disability and seizures. Proc Natl Acad Sci U S A 112:949-956. CrossRef Medline

Neves G, Cooke SF, Bliss TV (2008) Synaptic plasticity, memory and the hippocampus: a neural network approach to causality. Nat Rev Neurosci 9:65-75. CrossRef Medline

Nguyen TV, Lee JE, Sweredoski MJ, Yang SJ, Jeon SJ, Harrison JS, Yim JH, Lee SG, Handa H, Kuhlman B, Jeong JS, Reitsma JM, Park CS, Hess S, Deshaies RJ (2016) Glutamine triggers acetylation-dependent degradation of glutamine synthetase via the thalidomide receptor cereblon. Mol Cell 61:809-820. CrossRef Medline

Nguyen TV, Li J, Lu CJ, Mamrosh JL, Lu G, Cathers BE, Deshaies RJ (2017) p97/VCP promotes degradation of CRBN substrate glutamine synthetase and neosubstrates. Proc Natl Acad Sci U S A 114:3565-3571. CrossRef Medline

Pak DT, Yang S, Rudolph-Correia S, Kim E, Sheng M (2001) Regulation of dendritic spine morphology by SPAR, a PSD-95-associated RapGAP. Neuron 31:289-303. CrossRef Medline

Papuc SM, Hackmann K, Andrieux J, Vincent-Delorme C, Budișteanu M, Arghir A, Schrock E, Țuțulan-Cuniță AC, Di Donato N (2015) Microduplications of 3 p26.3p26.2 containing CRBN gene in patients with intellectual disability and behavior abnormalities. Eur J Med Genet 58: 319-323. CrossRef Medline

Pavlowsky A, Chelly J, Billuart P (2012) Emerging major synaptic signaling pathways involved in intellectual disability. Mol Psychiatry 17:682-693. CrossRef Medline

Phillips JR, Hewedi DH, Eissa AM, Moustafa AA (2015) The cerebellum and psychiatric disorders. Front Public Health 3:66. CrossRef Medline

Rajadhyaksha AM, Ra S, Kishinevsky S, Lee AS, Romanienko P, DuBoff M, Yang C, Zupan B, Byrne M, Daruwalla ZR, Mark W, Kosofsky BE, Toth M, Higgins JJ (2012) Behavioral characterization of cereblon forebrainspecific conditional null mice: a model for human non-syndromic intellectual disability. Behav Brain Res 226:428-434. CrossRef Medline

Ronstedt K, Sternberg D, Detro-Dassen S, Gramkow T, Begemann B, Becher T, Kilian P, Grieschat M, Machtens JP, Schmalzing G, Fischer M, Fahlke C (2015) Impaired surface membrane insertion of homo- and heterodimeric human muscle chloride channels carrying amino-terminal myotonia-causing mutations. Sci Rep 5:15382. CrossRef Medline

Sailer CA, Kaufmann WA, Kogler M, Chen L, Sausbier U, Ottersen OP, Ruth P, Shipston MJ, Knaus HG (2006) Immunolocalization of BK channels in hippocampal pyramidal neurons. Eur J Neurosci 24:442-454. CrossRef Medline

Sheereen A, Alaamery M, Bawazeer S, Al Yafee Y, Massadeh S, Eyaid W (2017) A missense mutation in the CRBN gene that segregates with intellectual disability and self-mutilating behaviour in a consanguineous saudi family. J Med Genet 54:236-240. CrossRef Medline

Vaillend C, Poirier R, Laroche S (2008) Genes, plasticity and mental retardation. Behav Brain Res 192:88-105. CrossRef Medline

Vargesson N (2015) Thalidomide-induced teratogenesis: history and mechanisms. Birth Defects Res C Embryo Today 105:140-156. CrossRef Medline

Wallace ML, Burette AC, Weinberg RJ, Philpot BD (2012) Maternal loss of Ube3a produces an excitatory/inhibitory imbalance through neuron type-specific synaptic defects. Neuron 74:793-800. CrossRef Medline

Yang J, Seo J, Nair R, Han S, Jang S, Kim K, Han K, Paik SK, Choi J, Lee S, Bae YC, Topham MK, Prescott SM, Rhee JS, Choi SY, Kim E (2011) DGK regulates presynaptic release during mGluR-dependent LTD. EMBO J 30:165-180. CrossRef Medline

Zhu YX, Braggio E, Shi CX, Kortuem KM, Bruins LA, Schmidt JE, Chang XB, Langlais P, Luo M, Jedlowski P, LaPlant B, Laumann K, Fonseca R, Bergsagel PL, Mikhael J, Lacy M, Champion MD, Stewart AK (2014) Identification of cereblon-binding proteins and relationship with response and survival after IMiDs in multiple myeloma. Blood 124:536-545. CrossRef Medline 